\title{
How CEO Values and TMT Diversity Jointly Influence the Corporate Strategy Making Process
}

\author{
Werner H. Hoffmann ${ }^{1}$ Lukas Meusburger ${ }^{1}$
}

Received: 24 May 2016 / Accepted: 24 October 2017 / Published online: 13 November 2017

(C) The Author(s) 2017. This article is an open access publication.

\begin{abstract}
Understanding managerial behavior and its underlying motivations is of key interest in times where the role of business in society is generally viewed critically. While CEO influence on strategy making processes is almost undisputed, little attention has explicitly been paid to how CEO values and the characteristics of the top management team (TMT) interact in shaping corporate strategy making. This is surprising if one follows the assumption that top managers who work closely together will by necessity influence each other's actions. Hence, we would expect the CEO-TMT interface to be vital in understanding how leadership influences strategy making. To address this, we propose a model in which the personal values of the CEO have a direct effect on the characteristics of corporate strategy making processes yet where this association is moderated by TMT diversity. We test the model with data from Austria and Germany obtained through a large-scale survey conducted in spring 2015 and a follow-up survey conducted in fall 2015 and find general support for our model. CEO values geared towards self-transcendence (as opposed to selfinterest) seem to be associated with more formal strategy making processes, while values geared towards openness to change (as opposed to conservation) are found to be associated with more flexible and less externally open ones. TMT diversity moderates all of these relationships. Our results add to upper echelon theory as well as to strategy process research and highlight promising avenues for future research.
\end{abstract}

\footnotetext{
W. H. Hoffmann

Werner.hoffmann@wu.ac.at

L. Meusburger

Lukas.meusburger@wu.ac.at
}

1 Institute for Strategic Management, Vienna University of Economics and Business (WU Wien), Welthandelsplatz 1, 1020 Wien, Austria 
Keywords Strategy making process - Upper echelon theory $\cdot$ Chief executive officer (CEO) · Top management team · Personal values, survey

JEL-Classification $\mathrm{M} 0 \cdot \mathrm{M} 1 \cdot \mathrm{L} 1 \cdot \mathrm{L} 2$

\section{Introduction}

Understanding how executives shape the corporations they work for is, in essence, vital for all organizational science (Hambrick and Quigley 2014). While the interest in how the personal characteristics of leaders and leadership teams influence the workings of corporations ${ }^{1}$ can be traced back at least to the origins of upper echelon theory (Hambrick and Mason 1984), curiosity regarding the motivations behind these influences has arguably increased in recent years. This is partly due to business scandals, and the resulting quest for more responsible leadership (Maak 2007) and partly because the role of business in society is generally viewed more critically today than it was in the past (Carter and Greer 2013). The increased interest is highlighted in a multitude of recent contributions in renowned publications (e. $g$. Six et al. 2013; Wowak et al. 2016; Hambrick and Quigley 2014).

Many important relationships have been uncovered between (individual and team) leadership characteristics, such as personality factors (Peterson et al. 2003), political orientation or personal values (Chin et al. 2013), and different outcome variables, such as performance (Ling et al. 2007; Hambrick and Quigley 2014), innovativeness (Lefebvre and Lefebvre 1992; Ahn et al. 2013), corporate social responsibility (Hemingway and Maclagan 2004) or corporate strategy in general (Gupta 1984; Miller and Toulouse 1986). These findings have greatly enhanced our understanding of how organizations work. But they have also by no means been uniform, particularly with regard to top management team (TMT) effects. This is due in part to the underlying complexity: TMT diversity could, for example, improve organizational performance because of the larger skill pool available or hamper it because of team fragmentation or lack of behavioral integration (Buyl et al. 2011). Excellent summaries of upper echelon studies and theories (e. g. Carpenter et al. 2004; Nielsen 2010) exist, and while this paper does not attempt to provide another compendium of findings, we do see several shortcomings that need to be addressed.

First, much of the prior upper echelon research uses performance as an outcome variable. We believe that studies which relate leadership to financial performance are unsatisfying as they fail to address the processes by which this relationship actually unfolds. While some of these processes have been explored, only a few have received sound empirical attention (Peterson et al. 2003). We argue that part of the reason for the equivocal results of past research into leadership characteristics (Kisfalvi and Pitcher 2003) lies precisely in the focus on outcomes that are fairly distal to the CEO, such as performance (Wowak et al. 2016; Hambrick and Quigley 2014). Of course, not all upper echelon research uses performance as the dependent vari-

\footnotetext{
${ }^{1}$ We use the terms corporation, firm and organization, by which we mean large firms/corporations/ organizations, interchangeably in this paper.
} 
able; relationships to proximate outcome variables (e.g. strategic dynamism) have also been analyzed and proved to be significant (Chatterjee and Hambrick 2007). However, almost none (with a few notable exceptions like Miller et al. (1998), who relate TMT diversity to strategic decision making or already mentioned Wowak et al. (2016), who look at effects of CEO charisma on strategic change) use the strategy making process itself as the outcome variable. This lack of attention is surprising given that this process describes "how managers can continuously influence the quality of the firm's strategic position" (Chakravarthy and Doz 1992). Understanding how leadership characteristics influence strategy making processes would seem to us to be vital for comprehending why these processes are structured the way they are and what characteristics are needed to continuously adapt organizations to fast changing environments.

Second, interaction effects have likewise not received adequate attention. Some past studies have analyzed and found various CEO characteristics to be important determinants of organizational outcomes (e. g. Chatterjee and Hambrick 2007). Others have looked at how the characteristics of TMTs (especially diversity) influence strategically relevant decisions (e.g. Hambrick et al. 1996). Despite the vast knowledge about the influence of leadership on organizations that these studies have produced, we are still somewhat puzzled by the fact that there have been only limited attempts to explicitly investigate how the characteristics of the TMT and the personality of the CEO interact and jointly shape strategic outcomes. After all, it would seem logical that the interactions between executives who work closely together by necessity influence their individual actions. Hence, to understand the influence of one particular person, interaction effects need to be taken into account. The few studies that have been conducted in this regard show promising results. Buyl et al. (2011), for example, analyze how CEO functional diversity interacts with TMT diversity in shaping organizational performance and postulate that having a generalist CEO partly substitutes for TMT functional diversity. Peterson et al. (2003), on the other hand, investigate how the personality of the CEO influences TMT group dynamics and find support for interaction effects on organizational performance. They also affirm the link between personality and organizational outcomes and call for more research to specifically explore the CEO-TMT interface. Finally, Papadakis and Barwise (2002) explore how CEO and TMT characteristics influence strategic decisions in Greek firms. While their results suggest that context matters most, they also submit that analyzing the influences of the CEO and the TMT jointly in upper echelon studies would provide a more reliable description of the underlying processes and dynamics. So, while these studies demonstrate the presence of interactions, none of them relate CEO-TMT interactions to a comprehensive model of strategy making.

Third, when people justify their intended behavior, they usually refer to their values (Roccas et al. 2002). This arguably makes these the most interesting subject of study when it comes to understanding managerial behavior. Yet in prior upper echelon research, values have mostly been assessed using proxies (e. g. demographics). Recent research questions the validity of this approach, with some researchers even calling for "[...] a moratorium on the use of demographic variables as surrogates for psychosocial constructs" (Boal and Hooijberg 2001, p. 523). We believe that there 
are advantages to using self-reported values over inferring them from observable characteristics. Any inference from observable action can always only be a secondbest guess. This applies especially for values that do not necessarily produce measurable actions and only guide behavior in a given situation. Accordingly, it could well be the case that two people with the same value systems act differently because they face different constraints (Schwartz 1994). Similar debates on self-reported psychological constructs have taken place in other disciplines (such as happiness research), where much attention has been devoted to testing the validity of self-reports, predominantly with positive results (Layard and Layard 2011). Nonetheless, using self-reported data does carry risks, such as construct validity or measurement error. However, since we use a widely-tested scale and follow best practice in our data collection, we believe that we have minimized these risks in our study. Furthermore, many of the possible drawbacks of using self-reported data are actually also present when using non-self-reported data (Chan 2009). We thus believe that our study puts us in a position to find more accurate explanations of CEO effects.

All in all, the above arguments constitute a call for a comprehensive interaction model. In response, we thus investigate the individual and joint effects of CEO values and TMT diversity on the characteristics of corporate strategy making processes. We position our paper at the intersection between upper echelon theory and strategy process research and consistently root it primarily in these two streams of literature. We deliberately chose the strategy making process as our outcome variable, since we feel that (a) the CEO has sufficient discretion to influence this process directly, and (b) the strategy making process itself has an important effect on corporate strategies and hence on performance (Hart and Banbury 1994; Covin et al. 2006; Baum and Wally 2003). We consider studying the influence of such personal values on a process outcome to be of key interest at a time like the present where responsible leadership is increasingly called for (Maak 2007), profit maximization is decreasingly seen as the only purpose of a firm (Carter and Greer 2013) and fast-changing environments require firms to continuously engage in self-renewal (Doz and Kosonen 2008).

For the purposes of this paper, we model the characteristics of the strategy making process along four dimensions derived from pre-existing frameworks and some very recent research, namely centralization, formalization, flexibility and external openness. Our data stems from a large-scale survey of CEOs in Austria and Germany carried out in early 2015 and a follow-up survey conducted with a secondary respondent in each corporation in fall 2015. Our hypothesized model claims that CEO values directly shape the corporate strategy making process and hence determine its characteristics. We also argue that higher levels of TMT diversity mitigate the association between CEO personal values and the characteristics of the strategy making process.

Our analysis of this data shows no support for the hypothesized model on a very high order level of strategy making process characterization (i. e. centralization vs. decentralization), yet does indicate some support for the model on a lower level of strategy making process characterization (formalization, flexibility, external openness), where the data backs most of our hypotheses. We can observe, for instance, that the values of CEOs geared towards self-transcendence seem to be associated with more formal strategy making processes, while those of CEOs geared towards 
openness to change appear to be linked with strategy processes that are more flexible yet less open to external stakeholders. In our model, more TMT diversity negatively moderates the association between $\mathrm{CEO}$ values and the strategy making process, which supports our interaction hypothesis.

Our paper thus adds to upper echelon theory and strategy process research alike. One of its main contributions lies in its integration of research on CEO-TMT interaction with an explicit treatment of values. We thus build on the sparse interaction papers outlined above and add a further nuance to upper echelon research, namely the notion that TMT diversity negatively moderates CEO influence on corporate outcomes. We also blend existing, comprehensive strategy making frameworks and add the very topical concept of external openness, thus contributing to strategy process research. In doing so, our paper provides a starting point for further research into the relationship between open strategy and other strategy process characteristics. Finally, we relate the two previous topics and test the model in a large-scale survey. The support we find for some of our hypotheses lends further emphasis to the above arguments. Overall, the paper contributes to our understanding of how and why CEOs structure strategy processes in certain ways and provide avenues for future research, particularly with regard to external openness.

\section{Background, Theory and Hypotheses}

\subsection{The Strategy Making Process}

There are a number of definitions for the strategy making process. Chakravarthy and Doz (1992) describe it as "how effective strategies are shaped within the firm and then validated and implemented efficiently". Referring to the diversity of strategy process research, Van de Ven (1992) argues that it can hardly be subsumed under a single paradigm and calls for the use of very explicit process definitions. He suggests three meanings of process: (1) a logic that explains causal relationships between independent and dependent variables, (2) a category of concepts that refers to actions of individuals or groups of individuals, and (3) a sequence of events that describes how things change over time. Pettigrew (1997) builds on this third definition and adds a number of premises to the study of strategy making processes, foremost the importance of temporal and contextual interconnectedness. Following this line of thought, and given that it is shaped by (also changing) people, a strategy making process is not a static 'thing' that a corporation has, but rather an eclectic process, which is itself subject to change in the long run. Each corporation will at a given point in time have a strategy process that features certain characteristics. These characteristics then constitute a dynamic organizational capability (Hutzschenreuter and Kleindienst 2006). The fact that they can be knowingly changed makes them an interesting topic of research. In fact, many different such characterizations-which Dess et al. (1997) refer to as "gestalts"-have been proposed. In this paper, we take the strategy making process to include all actions of individuals and groups of individuals that lead a firm to obtain, advance and alter its strategy. We also focus explicitly on the characteristics of strategy making processes. We assess these along 
the four dimensions mentioned above, which we see situated on two different levels (a classification which we will elaborate upon in the following paragraphs).

The first of these previous strategy making frameworks we briefly want to highlight is proposed by Dess et al. (1997) and builds on four different factors, which they label participative, entrepreneurial, adaptive and simplistic. They focus, however, on the entrepreneurial strategy making mode, i. e. a pro-active, partly risky and innovation-first approach, which they consider to be well suited to addressing the challenges of a fast-paced world. In their opinion, an entrepreneurial firm is the opposite of a conservative one. They do, however, also note that "[...] environmental challenges and organizational complexities [...] suggest that simple relationships may be inadequate to explain the relationship between entrepreneurial strategy making and performance" (Dess et al. 1997, p. 678).

Following on from other frameworks (with more dimensions) that they had proposed as early as 1978, Miller and Friesen (1983) define two strategy making dimensions, namely analysis and innovation. The former focuses on the number of factors that are taken into account for decision making, how well different decisions are integrated and the extent to which future contingencies are included. The latter deals with the amount of effort that is directed to the development of new products and/or services and how proactively and flexibly the corporation approaches strategic decisions. Miller and Friesen argue and show that firms must adapt their strategy making to the respective environment (which they again classify according to a number of categories).

In addition to his well-known distinction between planned and emergent strategies, Mintzberg also proposes several modes of strategy making, including the planning, adaptive, entrepreneurial and bargaining modes. These are defined in line with the roles that formal analysis, stakeholder concerns, interactions between multiple decision makers and opportunity/risk taking play in strategy formulation (Mintzberg 1978, 1973, 1983).

Probably one of the most comprehensive characterizations of strategy making to date is, however, the one proposed by Hart (1992), who endeavors to bring structure into the "model proliferation" (Hart 1992) that had resulted from the numerous typologies proposed over the years. He argues that the range of approaches that had emerged was so wide that little cumulative knowledge had in fact resulted. Hart builds on many previously suggested classifications and identifies the relevant and recurring themes as rationality (bounded vs. comprehensive), vision (where and how does it originate?) and involvement (i. e. who plays what role in the process?). Arguing that each of the previously suggested classifications only captures a portion of strategy making, he develops a comprehensive framework built around the role played by top management and other members of the organization in the development of strategy. This framework consists of five pure-type strategy styles-command, symbolic, rational, transactive and generative-each of which describes a mode of strategy making. In a command mode, for instance, the TMT formulates strategy top down, and organizational members implement it. In contrast, a generative mode of strategy making relies on central guidelines and intrapreneurship to produce innovation bottom up. Hart treats these styles as nonrival and contends that an ability to master multiple styles has positive performance 
implications, whereas single modes of strategy making are really only successful in turbulent environments where the need for fast processes outpaces deep capabilities (Hart and Banbury 1994). Hart's ideas are also taken up by Andersen (2004, 2009), who go a step further and argue that most strategy making typologies capture (de-)centralization as a dominant process characteristic.

In order to relate the individual characteristics of strategy making processes to those of leadership and to account for some very recent research trends a slight reconfiguration of the previous strategy making frameworks is wanted. As a starting point, we concur with almost all of the previous research (Hart 1992; Andersen 2004; Floyd and Lane 2000) on the central importance of the respective roles of top management, middle management and operative personnel in strategy making which addresses Hart's (1992) involvement theme. We label this the (de-)centralization dimension. Decentralization can occur on either a hierarchical, functional or geographic level or, indeed, as a combination of the three. Further components include the level of participation in decisions and decision authority accorded to the respective groups, both of which contribute (albeit in different ways) to decentralized strategy making (Andersen 2004). Decentralization is arguably the highestorder characteristic of strategy making in a firm.

In our opinion, there are three further dimensions which are subordinate to the level of decentralization in strategy making. The first of these, formalization, relates specifically to how well strategy making routines are established and codified and the extent to which medium- to long-term planning is emphasized within the firm (Ansoff 1980; Hart and Banbury 1994; Falshaw et al. 2006). It describes the level of formal analysis that a firm practices in its strategy formulation process. Furthermore, a formal strategy making process is also likely to be a procedure that occurs in regular cycles. This addresses in particular the rationality theme identified both by Hart (1992) and as early as 1963 by Cyert and March.

The second such dimension, namely flexibility, relates to the extent to which processes and the underlying assumptions behind established routines would be challenged should the respective environment change (Sharfman and Dean 1997). It also incorporates how well a corporation is able to accommodate new ideas and approaches (e.g. emergent strategies) from within (Mintzberg 1978, 1994). This dimension thus addresses the top-down vs. bottom-up theme (jointly with decentralization) and ties in with the discussion surrounding the entrepreneurial orientation of firms. The importance of (a lack of) flexibility becomes particularly evident in the analysis of firms which failed in times of major changes in their environments (Doz and Kosonen 2008).

The final dimension is external openness, which itself combines two distinct concepts, namely stakeholder engagement and open strategy. Stakeholder engagement is the extent to which stakeholder interests are considered in the formulation of the strategy (Freeman et al. 2010). Open strategy (Whittington et al. 2011; Matzler et al. 2014) relates to how far external stakeholders (such as universities, customers or NGOs) are given an active role in the strategy making process - a concept with close ties to open innovation practices (Laursen and Salter 2006). While the other three dimensions (decentralization, formalization and flexibility) feature directly in previously suggested frameworks, external openness has so far been more or less 
neglected. Technological possibilities such as crowdsourcing platforms and online communities have, however, greatly facilitated the adoption of more open approaches in recent years. It therefore comes as no surprise that several experts, including Chesbrough and Appleyard (2007), have pointed to a number of anomalies in the closedstrategy approach and to the inevitability of a paradigm shift towards a more open approach. The recently established academic interest in open strategy seems to prove their point and warrants this additional dimension in our strategy making framework.

These four dimensions are non-rival, non-exclusive and all present simultaneously-albeit to differing extents-in a single corporation. They characterize strategy making for a specific corporation. All in all, we believe that our framework, which both recombines and adds to existing models, provides a comprehensive account of all relevant dimensions of strategy making. Furthermore, because it treats these dimensions separately and does not summarize them in strategy making "characters", it provides the perfect basis for relating them to leadership characteristics.

\subsection{Upper Echelon Theory and Personal Values}

The idea behind upper echelon theory can be traced back to both the behavioral theory of the firm (Cyert and March 1963), which argued that managers do not always make rational choices, as well as to the notion that managers possess certain 'givens', which affect how they make certain decisions (March and Simon 1958). Hence, managers are fundamentally influenced by natural human limitations, such as bounded rationality, and by their own personal characteristics and cognitive biases. Hambrick and Mason (1984) took this as their starting point and developed a model of how managers' personal characteristics influence strategic choice. They referred to this model as "upper echelon theory". In this model, the so-called cognitive base and personal values act like a filter and lead to what Hambrick and Mason refer to as a limited field of vision. In this limited field of vision, managers still only notice what is relevant to them; Hambrick and Mason label this selective perception. Finally, managers interpret the perceived situation based on their respective 'givens'. The characteristics that guide the selective perception and interpretation of situations can be classified into psychological factors (values, cognitive base) and observable characteristics (age, education, culture of socialization, experience, etc.). Upper echelon theory differs from the general behavioral theory of the firm in its explicit focus on the characteristics of the TMT rather than on those of the individual executive (Tacheva 2007).

For Hambrick and Mason (1984), the TMT is the dominant coalition in an organization, i. e. its most powerful executives. While conceptually correct, this definition cannot be easily applied in practice, and we have therefore chosen to stick to the definition used in more recent reviews (e. g. Nielsen 2010), which describe the TMT as top executives who report directly to the CEO. Research into TMTs accords considerable attention to diversity — not just because of the high diversity in TMTs that has resulted from increased global mobility but also because diversity can have profound organizational outcomes (Tacheva 2007). TMT diversity is most commonly defined as the distribution of personal attributes among the members of the TMT (Nielsen 2010; Jackson et al. 2003). 
Multiple constructs can be used in conjunction with diversity, namely separation, variety and disparity. Diversity as separation means differences in opinions or positions and describes distance along a single continuum. Diversity as variety represents differences in knowledge, experience and so forth. Finally, diversity as disparity represents differences in pay or social assets. Like most other studies, we use a 'diversity as variety' definition across multiple categories for our study (see the section on methodology for a discussion of the variables used in our survey). We also acknowledge that a large body of literature has emerged (particularly in recent years) which investigates the micro-processes that constitute the actual connection between diversity and organizational outcomes such as intra-team processes. While some of this research argues that the diversity concept is too general to infer meaningful conclusions, it still enjoys wide support from the upper echelon community. However, since a full discussion of all these debates would go beyond the scope of this paper, we will restrict ourselves here to referring the reader to the many excellent existing reviews of this matter (e. g. Nielsen 2010).

Turning our focus explicitly to personal values takes us to a widely-researched field. Personal values have been shown to be important factors in determining (national) culture (Schwartz and Bilsky 1990; Schwartz and Sagiv 1995; Hofstede 1984), organizational culture (Schein 2009) as well as particular fields of strategic action, first and foremost in the stakeholder engagement and corporate social responsibility domains (Agle et al. 1999; Kaldschmidt 2011). Prior studies even show indirect links between values and corporate performance (Berson et al. 2008). A value system is an organization of beliefs relating to a preferred mode of conduct or end-state. Values are enduring, yet not fixed, and therefore different from personal traits (Rokeach 1973). While traits describe how people are, values describe what they deem good, what they see as desirable. Values are what people usually refer to when they justify actions and behaviors. In essence, traits are enduring dispositions, and values are enduring goals. Traits vary in the frequency and intensity of their presence; values vary in the relative importance attributed to them and thus serve as guiding principles (Roccas et al. 2002). Traits are also largely immune to environmental and social influences (e.g. education), while values are not (Olver and Mooradian 2003). According to McCrae and Costa (1996), traits like the five factors (one of the most common personality frameworks) are only the "raw materials" of personality, while values are concrete characteristic adaptations, habits, attitudes, etc. While traits guide an individual's behavior individually, it is the overall arrangement of their values, i. e. a person's overall value system, that determines how they interpret certain situations and hence how they choose to act. Values and traits are by no means independent of each other. Indeed, it has been argued that they can develop in parallel, i. e. that people may adjust their value systems to fit their traits, and that value priorities can induce behaviors that are then perceived as traits. Ultimately, we chose to use values in our study because the evidence points towards traits have a stronger influence on behavior over which individuals have little cognitive control, whereas values have more effect on behavior they can voluntarily control (Roccas et al. 2002) — and strategy making processes are closer to the latter than the former.

While numerous theoretical frameworks exist for values (e.g. Hofstede 1984; Rokeach 1973; Inglehart 2004), the most widely used system, particularly in 
Fig. 1 Schwartz Value Circumplex (Schwartz 1994)

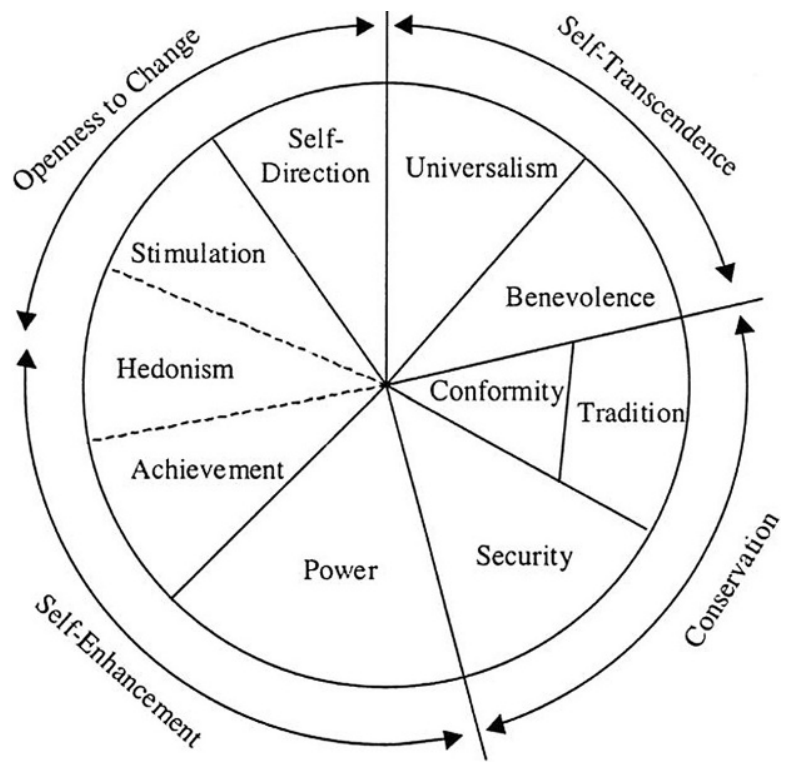

management research, is the Schwartz Value System (Schwartz and Bilsky 1990; Schwartz 1992). This was developed on the basis of the ideas put forward by Rokeach and presented in a seminal article in the anthology Advances in Experimental Social Psychology (Schwartz 1992), which has received more than 9000 citations to date. The system has been tested and verified using more than 200 samples from over 60 countries and continues to be widely applied in business and social research, for instance in the biennial European Social Survey (ESS), where it is used to measure the attitudes, beliefs and behavior patterns of diverse populations in more than 30 nations. The Schwartz Value System is based on the notion that values (a) are beliefs, (b) are a motivational construct, (c) transcend specific situations, (d) guide selection or evaluation, and (e) are ordered by relative importance. The framework consists of ten basic values, namely self-direction, stimulation, hedonism, achievement, power, security, conformity, tradition, benevolence and universalism (see Appendix for a more detailed description). These ten values are arranged in a circular manner (see Fig. 1) in recognition of their competing nature. This means that actions that are guided by one value may be in conflict or in accordance with other values. As Fig. 1 shows, the closer the motivational goals of two or more values, the more they correlate empirically and the more closely they are located in the circular representation (Roccas et al. 2002). The ten basic values in the Schwartz Value System can also be grouped into two basic dimensions on orthogonal axes, thereby depicting two fundamental human problems which require resolution (Rohan 2000). The respective values upon which these basic dimensions are built can also be seen in Fig. 1. The first of these two dimensions is openness to change vs. conservation (i. e. enhancement of the status quo by following intellectual and emotional interests vs. preservation of the status quo for various reasons, e. g. tradition). The second dimension is self-transcendence 
vs. self-enhancement (i.e. concern for the welfare of others and society vs. selfinterest) (Lindeman and Verkasalo 2005). This type of focus on higher-order values is useful because it allows us to compare whole values systems in relation to an external variable instead of concentrating on single values at an individual level (Schwartz, 1996 quoted from Kaldschmidt 2011). This recognizes the fact that opposing values are activated in the face of moral decision making, which can lead to ethical dilemmas (Watson et al. 2009). In such cases, a decision will then often be taken based on the importance attributed to any of the relevant competing values (Schwartz 2013). Since such moral decisions clearly feature in everyday managerial work, these values are highly important for understanding the behavior of managers.

\subsection{Hypotheses}

Values influence the strategy making process in multiple ways (Hambrick and Brandon 1988). Prominent in upper echelon theory, for instance, is the notion that the personal values held by CEOs will influence their decisions by shaping their interpretations of a situation and acting like a filter for environmental stimuli (Hambrick and Mason 1984). Arguably, decisions on how to structure a corporation's strategy process are-like other strategic decisions-dependent on situational interpretations. The conscious transfer of values to the organization is a second way in which they can exert an influence. A characteristic of values is that their holders view them as favorable. Executives thus imprint their own values onto their organization by means of their decisions (Berson et al. 2008). Internal processes are one clear manifestation of decisions. In other words, the ethical orientation of an organization, for example, is revealed through the formal and explicit processes it uses in its day-today activities (Hood 2003; Carlson and Perrewe 1995). We can also expect values to have an indirect effect through employees, since CEOs are likely to-knowingly or unwittingly_project and communicate their own values onto their employees either directly or by acting as a role-model, thereby encouraging or discouraging particular behaviors and behavioral patterns (Schein 2010). In the strategy making context, a corresponding behavioral pattern would, for instance, be the voicing of individual ideas by employees, which might be welcome to a greater or lesser extent in a corporation. The resulting environment also shapes and constitutes an important part of the respective corporation's strategy making process (Burgelman 1996).

As mentioned above, we focus in our study on two prime value dimensions from which a number of behavioral tendencies follow. A value system geared towards self-transcendence (as opposed to self-enhancement) means that the well-being of others is given a high priority and drives the importance attached to environmental protection and equality. People with high self-transcendence values tend to be more tolerant and less concerned about social status, control and dominance over others (Roccas 2003). In contrast, the holder of a value system geared towards openness to change (as opposed to conservation) places great importance on independent action and shows little concern for the status quo. Such people are, for example, unlikely to be strong proponents of tradition and/or religion (Kaldschmidt 2011). As we will explain below, these behavioral tendencies also materialize in more specific ways when viewed in the strategy making context. 
The first and highest-level dimension of strategy making we would like to relate to values is decentralization, which many previous frameworks identify as one of the most important dimensions of strategy making (Andersen 2004). Decentralized organizational designs by necessity imply more people having stakes in decisions and thus more opinions on the table at any given time. CEOs with a value system geared more towards openness to change are comfortable with letting different opinions surface and are open to allowing people on lower levels to take decisions without having prior knowledge themselves of where these might lead (Sashkin 1988). Such values have also been found to be positively correlated with more riskseeking personalities (Roccas et al. 2002). Lewin and Stephens (1994), for example, argue that managers who are more risk-averse are more likely to implement more centralized organizational designs, because such setups are characterized by high levels of control and supervision to minimize uncertainty and reduce surprises. We would thus expect to see a positive relationship between openness to change and decentralization. On the other hand, people whose value systems tend more towards self-transcendence (as opposed to self-interest) are less concerned about "making a mark" for themselves, have less need to improve their social status and less desire to influence the context in which they operate (Papadakis 2006). More selftranscendence values also imply that more weight is placed upon equality (Roccas 2003). CEOs with such values seek to design organizations and strategy processes with only minimal power differences and would thus be expected to adopt a very decentralized design in their strategy processes (Lewin and Stephens 1994). Conversely, more pronounced self-enhancement values have been shown to lead to more centralized organizational designs: the more CEOs are driven by self-enhancement and achievement values, the more need they will feel to be personally and directly responsible for success. This is only achievable in more centralized structures (Miller and Droege 1986). These findings have also been partly replicated in recent research (Papadakis 2006). Accordingly, we should expect to see an association between selftranscendence values and decentralization.

H1a: CEO values more oriented towards openness to change are associated with higher scores for decentralization

H1b: CEO values more oriented towards self-transcendence are associated with higher scores for decentralization

Formalization is the dimension that is most closely related to rationality (Hart 1992) and the so-called planning school of strategy making (Ansoff 1965). It implies written rules and procedures (e.g. job descriptions), thorough data collection and in-depth analyses prior to decisions as well as sophisticated control mechanisms (Wally and Baum 1994). These rules and procedures limit the amount of personal power that can be projected onto the organization and how far an organizational design can be adapted to suit one's own personal needs. If procedures in an organization are more formalized, agendas guided purely by self-interest, be they illegal or not, have less potential to succeed. Similarly, there is less chance of a position of power being abused. Unsurprisingly, research shows that more advanced governance mechanisms reduce the probability of accounting scandals and indeed of fraud in 
general (Agrawal and Chadha 2005; Farber 2005). Accordingly, we would expect CEOs with more pronounced self-enhancement values (which are augmented by power values) to build less formalized organizations. Vice versa, we would expect CEOs with more pronounced self-transcendence values to implement more formalized strategy making processes in order to ensure that self-interest agendas are kept to a minimum.

If CEOs have a value system that is oriented more towards self-interest, they are also more likely to assume similar value systems in other members of their organization. Guth and MacMillan (1986) investigated the link between self-interest and middle management strategy implementation and found that if a strategic initiative threatens their self-interest agendas of middle management at risk, they are more likely to create substantial obstacles to its implementation. It thus seems reasonable to assume that managers who expect their subordinates to be guided by self-interest agendas will implement formal mechanisms that ensure compliance with top-down agendas. Conversely, Lewin and Stephens (1994) suggest that managers who exhibit a high level of trust in the good of people feel little need to monitor employees and thus tend to implement fewer formal control and governance mechanisms. These arguments lead us to the following hypothesis:

H2: CEO values more oriented towards self-transcendence are associated with higher scores for formalization

CEOs with stronger openness to change values tend to attribute less importance to the status quo or to established routines and behavioral norms (Schwartz 1992). Hence, they could be expected to depart more frequently from the status quo and encourage more flexible strategy making processes - an expectation that is backed up by some very recent research (Wowak et al. 2016). Likewise, and as outlined above, openness to change values are associated with greater tolerance for risk (Roccas et al. 2002). People with such values have fewer reservations regarding ambiguity. While flexibility in strategy making is not necessarily a high-risk approach, it does require the challenging of previously held assumptions. If the latter relate to the very foundations of the workings of the corporation, it would seem safe to assume that challenging them increases ambiguity.

A flexible strategy making process also facilitates the integration of entrepreneurial, emergent and bottom-up strategic initiatives into overall corporate strategy. Many authors, including Burgelman (1983), have suggested that top-down, induced strategic initiatives produce little variation to the existing course of action and that it is the more bottom-up, autonomous activities that bring about major changes. Since CEOs with more pronounced openness to change values can be expected to be more welcoming of (or even demanding) such changes, it seems likely that they would implement strategy making processes that afford the necessary flexibility. In contrast, we explicitly do not expect a negative association between openness to change and formalization, since the latter does not, in our view, prohibit or prevent the former. Indeed, formalization that is "done well" might even increase information flows and speed up strategic decisions (Baum and Wally 2003) and thus be an additional driver of flexibility. 
H3: CEO values more oriented towards openness to change are associated with higher scores for flexibility

When a strategy making process is more externally open, stakeholders outside the firm are included in strategy formulation. This is achieved either by considering their interests (stakeholder engagement) (Freeman et al. 2010) and/or by actively engaging them in the process (Matzler et al. 2014). The logic behind externally open strategy making is simple: since there are more people outside a firm than within, the population of non-firm members must by default have more ideas than the firm members. A paradigm shift has taken place in this respect, and while strategy making used to be elitist and secret (Williamson 1970), more and more firms are now stepping beyond open innovation and seeking to harvest the potential of openness in their strategy making endeavors as well (Dobusch et al. 2015). However, more external openness also means that more opinions will be voiced (Whittington et al. 2011), and a firm thus willingly submits itself to these by being more transparent and/or inclusive. This means that it has to consider more alternative options, some of which will undoubtedly deviate from its current course of action. We would expect CEOs with value systems more oriented towards openness to change to foster such strategy making processes, since they are the ones who will recognize the greatest benefit in such alternative options. Hence, we would also expect to see a positive association between $\mathrm{CEO}$ values geared towards openness to change and the external openness of strategy making. In fact, similar results have already been reported. Ahn et al. (2013), for example, identified certain CEO traits, like risk-taking and entrepreneurial orientation, that are positively related to open innovation practices. The argument we have previously framed with respect to higher levels of flexibility inducing higher levels of ambiguity (which people with less tolerance for risk try to avoid) can also be transferred to external openness. Here too, more openness should be associated with higher levels of ambiguity (not least because of the potential for information and idea leakage), lending further support to the hypothesis that more openness to change values should be associated with more external openness.

H4: CEO values more oriented towards openness to change are associated with higher scores for external openness

CEOs can influence their corporations through their ability to exercise discretion (Hemingway and Maclagan 2004). The more discretion they have, the more they will imprint their values on the firm by designing processes according to what they view as 'good'. Finkelstein and Hambrick $(1987,1990)$ identify three factors that determine discretion, namely the degree to which the environment allows change, the degree to which the organization itself can accommodate change and the extent to which the CEO can envision multiple forms of action. More diverse TMTs tend to exhibit more cognitive diversity (Finkelstein and Hambrick 1996), which means that more alternative ideas and views are voiced. In most firms, the TMT plays an important role in major decisions that cannot be taken by the CEO alone. The greater the number of alternative views and ideas that circulate in the boardroom, the more unlikely it is that the CEO will be able to enforce all his/her own ideas. In other words, diversity limits consensus (Knight et al. 1999). Hence, it can be assumed that the greater the diversity in the TMT, the more it will act like a filter when it comes 


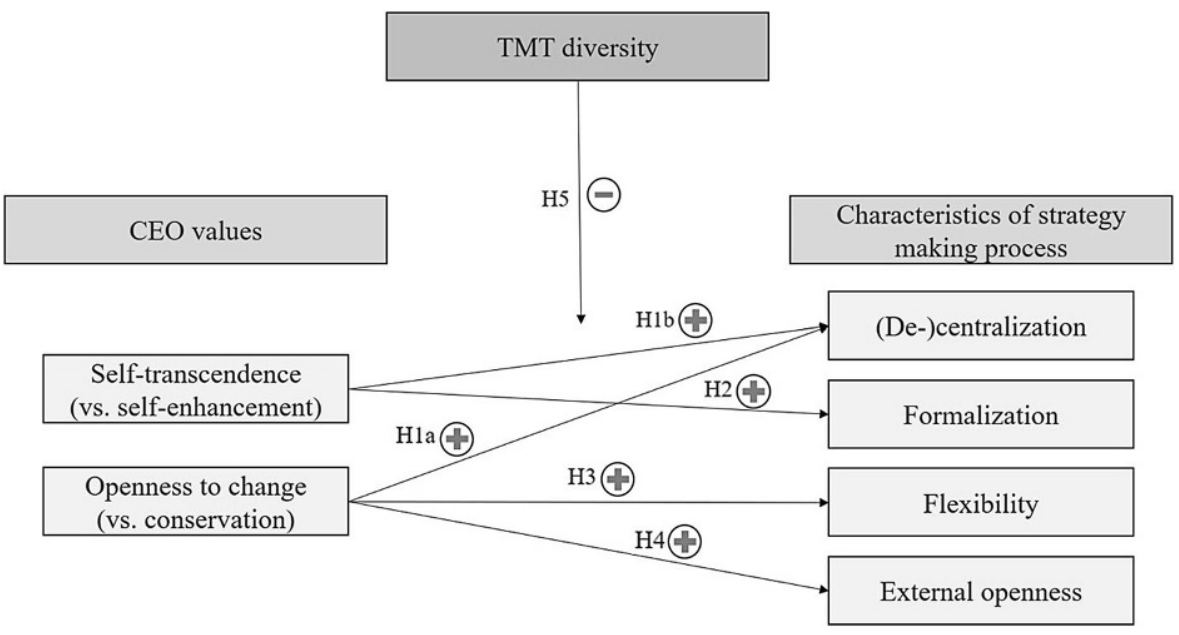

Fig. 2 Stylized model of relationships

to the CEO imprinting values onto the corporation. The same logic should apply to the relationship between the CEO and the strategy making process, and we would therefore expect TMT diversity to have a similar effect as a limitation of managerial discretion (Finkelstein and Hambrick 1990). In other words, we would expect it to limit the extent to which a CEO can simply implement processes at will.

We have already argued that CEOs can project their values onto the organization in their capacity as role models and thus also shape the organizational climate (Schein 2010). Yet the other members of the TMT are also likely to serve as role models. Hence, greater diversity in the TMT is likely to mitigate the role model effect of the CEO as the other TMT members (unknowingly) project different values onto the organization. We thus expect TMT diversity to moderate both of the ways in which CEO values influence strategy making processes, namely the intentional design of processes according to desired end-states and the unwitting projection of values. This leads us to the following hypothesis.

H5: Higher TMT diversity negatively moderates the relationship between CEO values and the characteristics of the strategy making process

Our five hypotheses are summarized in Fig. 2. As this graphic shows, higher levels of self-transcendence values should have an effect on (de-)centralization and formalization, openness to change values should have an effect on (de-)centralization, flexibility and external openness, while TMT diversity is expected to moderate all of these relationships.

\section{Methodology}

Strategy making processes are usually studied by means of observation or by asking key players directly (Chakravarthy and Doz 1992). Since we wanted to show 
a general link between the characteristics of strategy making processes and personal values, we needed a large sample. We therefore opted for the latter approach using a large-scale survey. Our sample selection was guided by the concern that strategy making quickly becomes simplistic below a certain firm size threshold (Kraus et al. 2006). For this reason, our sample was limited to the top corporations (measured by turnover) in Germany and Austria for which CEO data could be obtained. Overall, this sample included some 3000 firms. To test our hypotheses, a multi-item questionnaire was developed (in German). This questionnaire was extensively pre-tested with top executives in two-hour face-to-face interviews and refined accordingly. We also carried out a pre-test under normal survey conditions (i. e. in which the CEOs completed the questionnaire alone) with CEOs from firms that were not included in our sample. The improved questionnaire was then mailed to the CEOs of the 3000 companies in the sample. A total of 137 completed surveys were returned. This translates into a response rate of $4.6 \%$, which-while rather low-is acceptable for CEO studies (Friedman and Singh 1989; Agle et al. 1999). Since the questionnaires were personalized, we were able to match the responses with data from publicly available sources and the corresponding corporate websites. Given our fairly low response rate, non-response bias could have been a potential threat to the validity and reliability of our findings. We tested for non-response bias by comparing the responses of very early and very late respondents. This technique is based on the assumption that respondents who only reply after the original deadline and after multiple reminders are most similar to non-respondents (Wagner and Kemmerling 2010). We ran t-tests for all our major variables to test for significant differences in the responses of early (first quartile) and late respondents (fourth quartile). No statistically significant differences between early and late participants, either in our dependent, independent or control variables, could be identified in any of the cases. We do acknowledge, however, that our relatively small sample size and the rather large variance in firm sizes might be a potential obstacle for the generalizability of our results as we cannot convincingly argue that our sample is representative for the population to a sufficient degree. For this reason, we used turnover as a control variable in our models and did not find any significant effect (see below for details). This suggests that the spread in firm sizes is not likely to bias our results.

As in every survey, common method bias (or common method variance, CMV) can severely limit the validity of the findings. To avoid this methodological flaw, we relied on two remedies as suggested by Podsakoff et al. (2003). First, we ensured that the sequence of items minimized the likelihood of CMV. Introductory texts were also used to create an additional psychological separation between predictor and criterion variables. Second, we identified a second member of the TMT in each participating firm and sent out a follow-up survey five months after the initial survey to measure the dependent variables (i.e. the characteristics of the strategy making process). There were no particular reasons for this time lag other than the need to analyze the data from the prime respondent prior to contacting the second informant and the time it took to get the replies. Data from top executives is notoriously hard to obtain, and we invested a great deal of effort in ensuring a high response rate, including sending multiple reminder e-mails and phoning the potential participants to encourage them to participate. We received a total of 48 responses to our follow- 
up survey, which corresponds to a response rate of $35 \%$. Of these, 44 responses were usable for the analysis. We used the data generated thereby to validate the dependent variables of the prime respondents and to check for potential differences in results when the dependent variable from the validation survey was used instead of that from the primary survey.

\section{Analysis}

Our dependent variables are the different characteristics of the strategy making process. To construct the predictors, we took existing surveys of similar dimensions by Hart (1992) and Andersen (2004) as our starting point, included a minimum of two items on each characteristic and operationalized them using seven-point Likert scales. Variables were constructed by calculating the adjusted mean of the respective items from the questionnaire. We ran a confirmatory factor analysis (CFA) to ensure validity and reliability for the four dimensions used to characterize the strategy making process. We obtained a good model fit with an RMSEA of 0.062 and a CFI of 0.935 . Most items load on the predicted factor with a (standardized) value of around 0.8 , with only a few items exhibiting values slightly below 0.6 . Full details of the CFA are available from the authors upon request. A list of items for the constructs and their origins in literature is shown in Table 1. Alphas are provided in Table 2.

Table 1 Model constructs for characterization of the strategy process

\begin{tabular}{|c|c|c|}
\hline Construct & Questionnaire items & Derived from \\
\hline \multirow[t]{2}{*}{ Decentralization } & Participation of middle managers & Andersen (2004), Dess et al. (1997) \\
\hline & Participation of operative personnel & Andersen (2004), Dess et al. (1997) \\
\hline \multirow[t]{4}{*}{ Formalization } & Process regularity & Hart et al. (1994), Dess et al. (1997) \\
\hline & $\begin{array}{l}\text { Emphasis on analytics in strategy making } \\
\text { process }\end{array}$ & Hart et al. (1994) \\
\hline & $\begin{array}{l}\text { Emphasis on strategic medium- to long- } \\
\text { term planning }\end{array}$ & Andersen (2004) \\
\hline & Existence of a distinct strategy department & Papadakis et al. (1998) \\
\hline \multirow[t]{5}{*}{ Flexibility } & $\begin{array}{l}\text { Adaptation of tools according to specific } \\
\text { needs }\end{array}$ & Hart et al. (1994) \\
\hline & $\begin{array}{l}\text { Challenging routines and assumptions when } \\
\text { environment changes }\end{array}$ & $\begin{array}{l}\text { Hannan and Freeman (1984), Sharf- } \\
\text { man and Dean (1997) }\end{array}$ \\
\hline & $\begin{array}{l}\text { Presence of strategies which emerged with- } \\
\text { out being planned }\end{array}$ & Dess et al. (1997), Mintzberg (1978) \\
\hline & $\begin{array}{l}\text { Risk aversion in selection of strategic op- } \\
\text { tions }\end{array}$ & Hart et al. (1994), Dess et al. (1997) \\
\hline & Failure culture & Hart et al. (1994), Dess et al. (1997) \\
\hline \multirow{2}{*}{$\begin{array}{l}\text { External } \\
\text { openness }\end{array}$} & Stakeholder engagement ( 2 items) & Freeman et al. (2010) \\
\hline & $\begin{array}{l}\text { Stakeholder participation/open strategy } \\
\text { ( } 2 \text { items) }\end{array}$ & $\begin{array}{l}\text { Laursen and Salter (2006), Dess et al. } \\
\text { (1997) }\end{array}$ \\
\hline
\end{tabular}




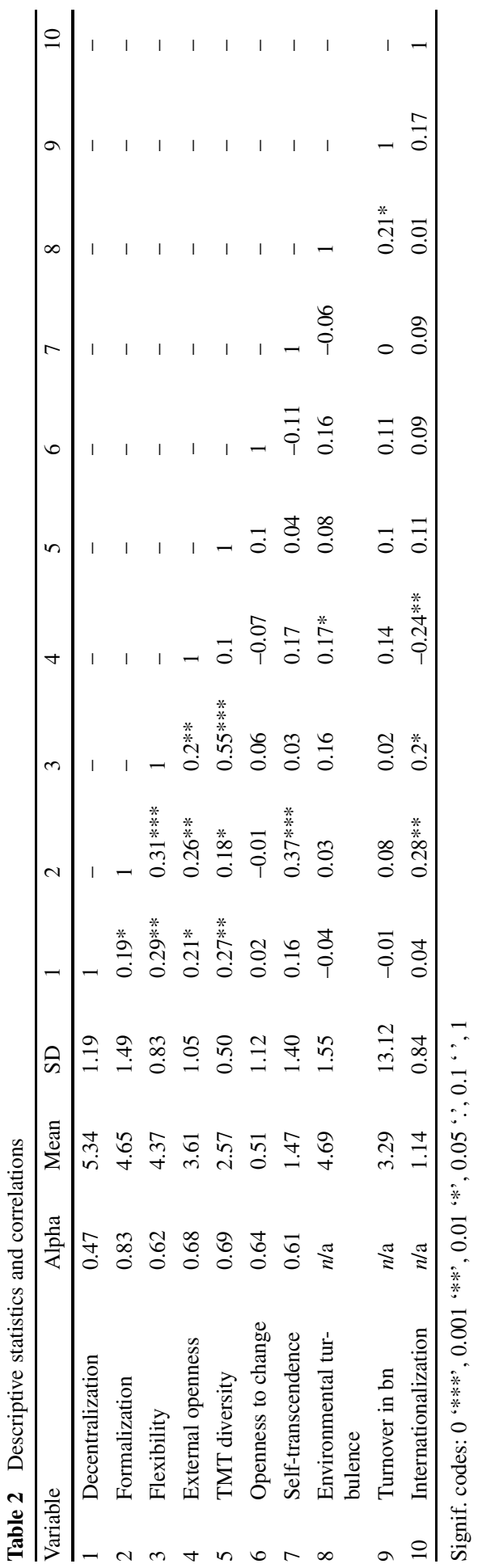


Our main independent variables are the CEO values, which were assessed according to the Schwartz Values Theory using the German translation of the Short Schwartz Value Scale (Boar 2013; Lindeman and Verkasalo 2005).

The two variables used in the analysis are the two highest-order variables, namely openness to change and self-transcendence (see above), which we obtained by aggregating the lower-order values into the respective higher-order values according the suggested methodology (Schwartz 1992). The variables are continuous, and a higher value for each means that the value system of the respective CEO is geared more towards this dimension than its counterpart on the respective axis (i. e. conservation and self-enhancement). We then needed a measure for TMT diversity. As already indicated, we used a "variety" based definition of diversity, which is arguably the most common one (Nielsen 2010). Recent advances in upper echelon theory have emphasized the importance of measuring diversity along multiple dimensions. We paid tribute to this insight and included functional background, social and geographical background, educational background and age as the basis for our measure (Nielsen 2010). It has also been suggested that it can be beneficial for empirical studies to study the single elements of TMT diversity separately (Williams and O'Reilly 1998). However, since we only use TMT diversity as a moderator, and not as prime predictor, we knowingly sacrificed construct validity for higher measurement reliability and ease of use (Nielsen 2010). Accordingly, we operationalized TMT diversity as a single construct in the analysis. This approach has generally found acceptance among researchers and practitioners (Jackson et al. 2003). Components were neither centered nor standardized because, as argued by Dawson (2014), the results would be the same regardless of standardization or not. We also conducted simple slope tests to test the significance of our moderation. While these suggest significance, their results have to be interpreted with caution given the arbitrary nature of the values chosen to conduct the tests (Dawson 2014).

Since it has been argued that firm size and complexity could be related to various aspects of strategy making and affect the relationship between personal characteristics of the management and organizational outcomes (Miller 1991), we included firm size by turnover and internationalization, measured on a three-point scale, as control variables. Both variables were derived from secondary, publicly available sources. Since the corporation's (industry) environment could also affect its strategy making process (Carpenter 2002), we also included environmental turbulence as an additional control variable. The relevant variables and their descriptive statistics are presented in Table 2. While the alphas for most variables are in an acceptable range, the alpha for decentralization is rather low, which casts some doubts over the assumption that our characterization of decentralization really does measure one construct. We will return to this point below in the discussion section. However, we would also like to offer another explanation for the rather low alpha levels. For the purposes of brevity in the questionnaire (which is essential to obtain replies from busy CEOs), we had to limit the number of items used to measure each variable. To measure CEO values, for example, we used the shortest tested scale available, with only 10 items (while scales with up to 57 items do exist, these are mostly used with students, who are far easier to persuade to complete lengthy questionnaires). An approach with only a few items per construct increases response rates, but leads 
by default to lower alphas, although this does not necessarily imply lower reliability (Field 2013).

To test our hypotheses, we ran a set of moderated OLS regressions. For each individual characteristic of the strategy making process, we ran a model with the respective characteristic (e.g. formalization) as the dependent variable and CEO values and TMT diversity as our independent variables. If a certain type of CEO values is associated with the respective strategy making process characteristic, we would expect the coefficient on the respective $\mathrm{CEO}$ value to be positive. To account for the hypothesized interaction effect between CEO values and TMT diversity, we included two moderation variables, which we obtained by multiplying the respective variables. Our independent variables also included the other characteristics of the strategy making process as controls to account for possible interaction effects which did not explicitly form part of the model. For each regression model, we began with the control variables only, then added the direct effects and finally the moderation variables. We also ran a model for each specification without the control variables, as this allowed us to run the model on a higher number of observations, since the control variables, especially turnover, could not be determined for all firms in the sample. Finally, we ran additional tests to check for potential endogeneity through omitted variable bias and for possible common method bias. We approached the former with a sub-sample analysis using only family firms with owner-CEOs, where reverse causality is extremely unlikely as CEO self-selection is not an option. In the latter, we used data obtained through our follow-up survey (see above). In doing so, we fully separated the observations for the independent and dependent variables and re-ran our analyses to confirm our results.

\section{Results}

We had hypothesized that the value orientation of the CEO would influence the characteristics of the corporate strategy making process, but that this effect would be negatively moderated by TMT diversity. Specifically, we argued that CEO values geared towards openness to change would be positively associated with decentralization (H1a), flexibility (H3) and external openness (H4), while CEO values geared towards self-transcendence would be associated with higher levels of decentralization (H1b) and formalization (H2). TMT diversity should moderate all of these associations (H5).

The analysis partly supports our hypotheses. First, we see no connection between CEO values and the highest-order characteristic of the strategy making process, decentralization (see Table 3, hypotheses in bold). The signs for the coefficients are correct in some of the model specifications, but the standard errors are far too high to infer meaningful conclusions. This holds for both the values we had hypothesized to be relevant for decentralization and is the same in all models. We thus cannot reject the null hypothesis in $\mathrm{H} 1 \mathrm{a}$ and $\mathrm{H} 1 \mathrm{~b}$ and have to conclude that there does not seem to be a direct association between CEO values and the level of decentralization in the strategy making process. We have endeavored to provide an explanation for this result in the discussion section. 


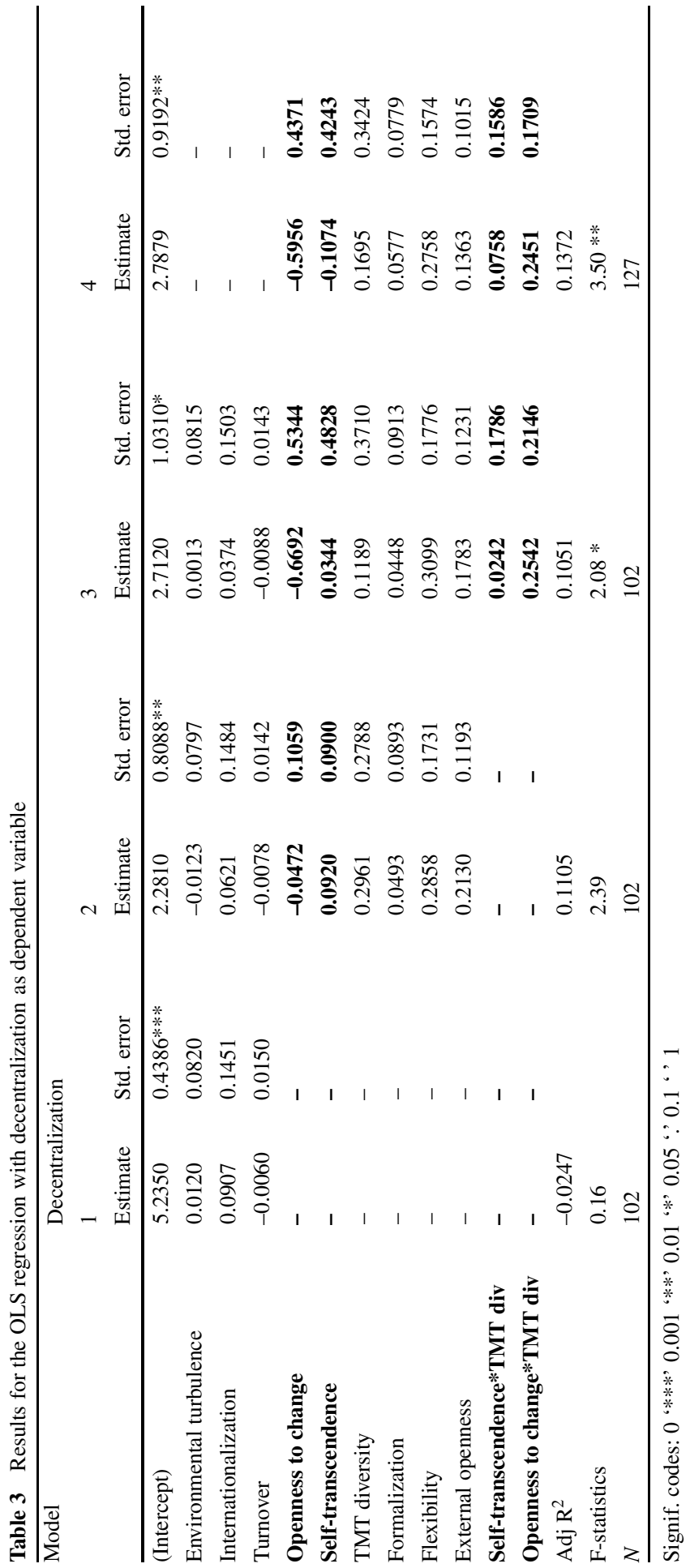


When we go a level lower, however, the analysis provides support for our hypotheses. As hypothesized, our data shows that CEO values geared towards selftranscendence are indeed associated with higher levels of formalization (H2; see Table 4). The coefficient on self-transcendence is positive and statistically significant at least at the 5\% level ( $p$-value $<0.5$ ) in all model specifications. In models 2 and 4 , the association is even significant at the $1 \%$ and $0.1 \%$ levels respectively. As expected, the coefficient of the self-transcendence*TMT diversity variable is negative and significant at the $10 \%$ level in the models where it is included, thereby supporting our hypothesis (H5) that higher TMT diversity negatively moderates the relationship between the CEO's personal values and the characteristics of the strategy process. The model fit is acceptable and highest in the model that includes the controls and the moderation variables. Two other results are also worth mentioning. First, we see a positive association between level of internationalization and formalization (significant at the $10 \%$ level). Since governing the more complex structures of international corporations requires more formal rules (Sanders and Carpenter 1998), this is an intuitive result. Second, the models show a positive association between formalization and flexibility, once again suggesting that the two characteristics are not independent of each other.

The data also supports our hypothesis that values geared towards openness to change are associated with more flexible types of strategy making processes $(\mathrm{H} 3$; see Table 5). The coefficient on openness to change is positive but not significant in model 2, yet as soon as the moderation variables are included, it becomes statistically significant at the $10 \%$ level in model 3 and rising to the 5\% level in model 4 , where we ran the regression without the controls in order to be able to use the larger sample size available. The coefficient on the moderation variable openness to change*TMT diversity is negative and significant in all models where it is included (10\% and 5\% significance level), lending support to our moderation hypothesis. In all the specifications, TMT diversity itself is also positively related to flexibility as theory suggests (Boeker 1997). Depending on the model, we also see significant positive associations between external openness and flexibility as well as between formalization and flexibility, both of which we had expected from theory. Model fit is even better than in the formalization model and, all in all, the regression model provides some support for our hypotheses regarding the flexibility dimension of the strategy making process (H3) and moderation (H5).

The results for external openness (Table 6) seem puzzling at first, as the data contradicts our hypothesis that CEO values geared towards openness to change would be associated with higher levels of external openness (H4). Indeed, the opposite would seem to be the case. The analysis shows a statistically significant but negative association between higher levels of openness to change and external openness. Higher levels of TMT diversity again moderate the relationship (statistically significant at the $10 \% / 5 \%$ levels depending on the model) and lower the negative association (H5). The results point in the same direction in all model specifications and imply that the less open a CEO is to change (i. e. the more conservationist a CEO is), the more stakeholders are included. This result not only contradicts our hypothesis, it is also intuitively puzzling, as it would seem logical to assume that stakeholder integration would lead to more alternative options and would thus be favored by a non- 


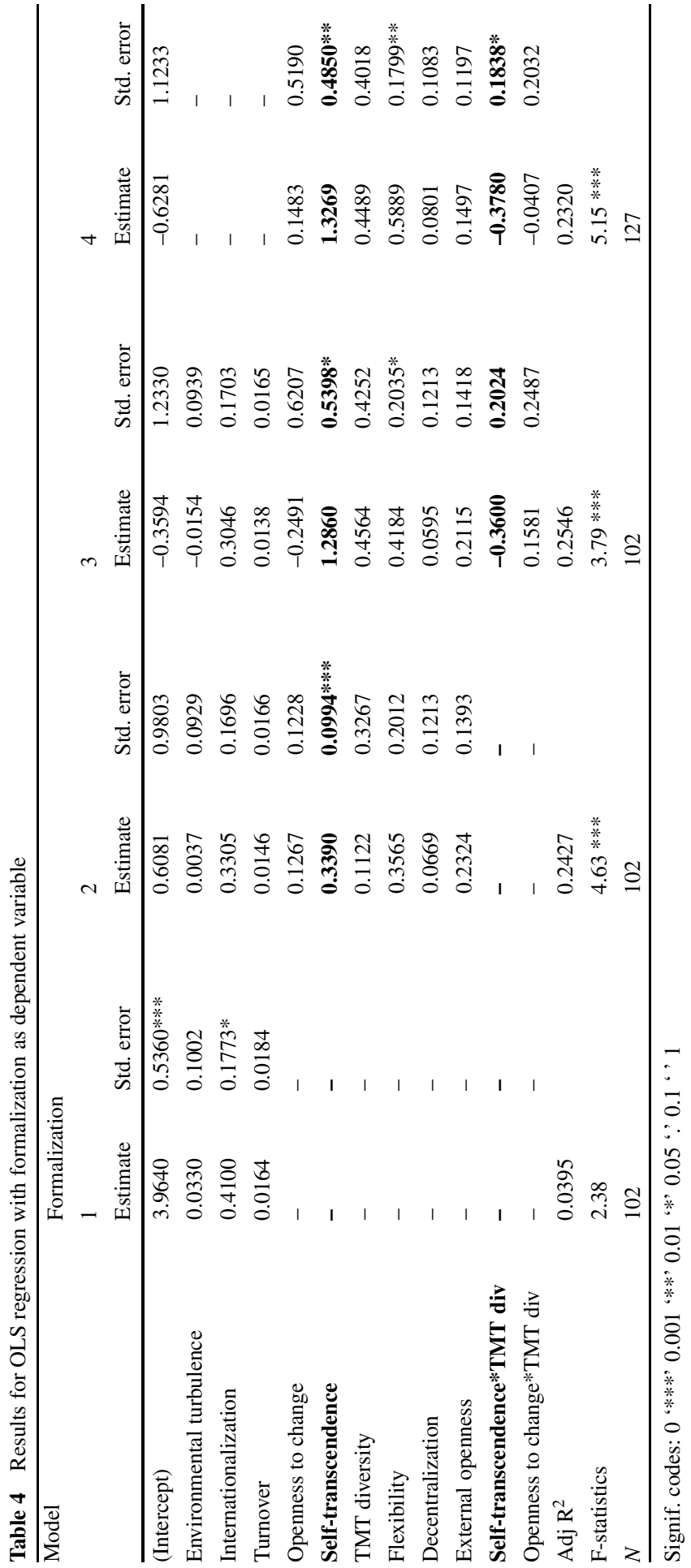




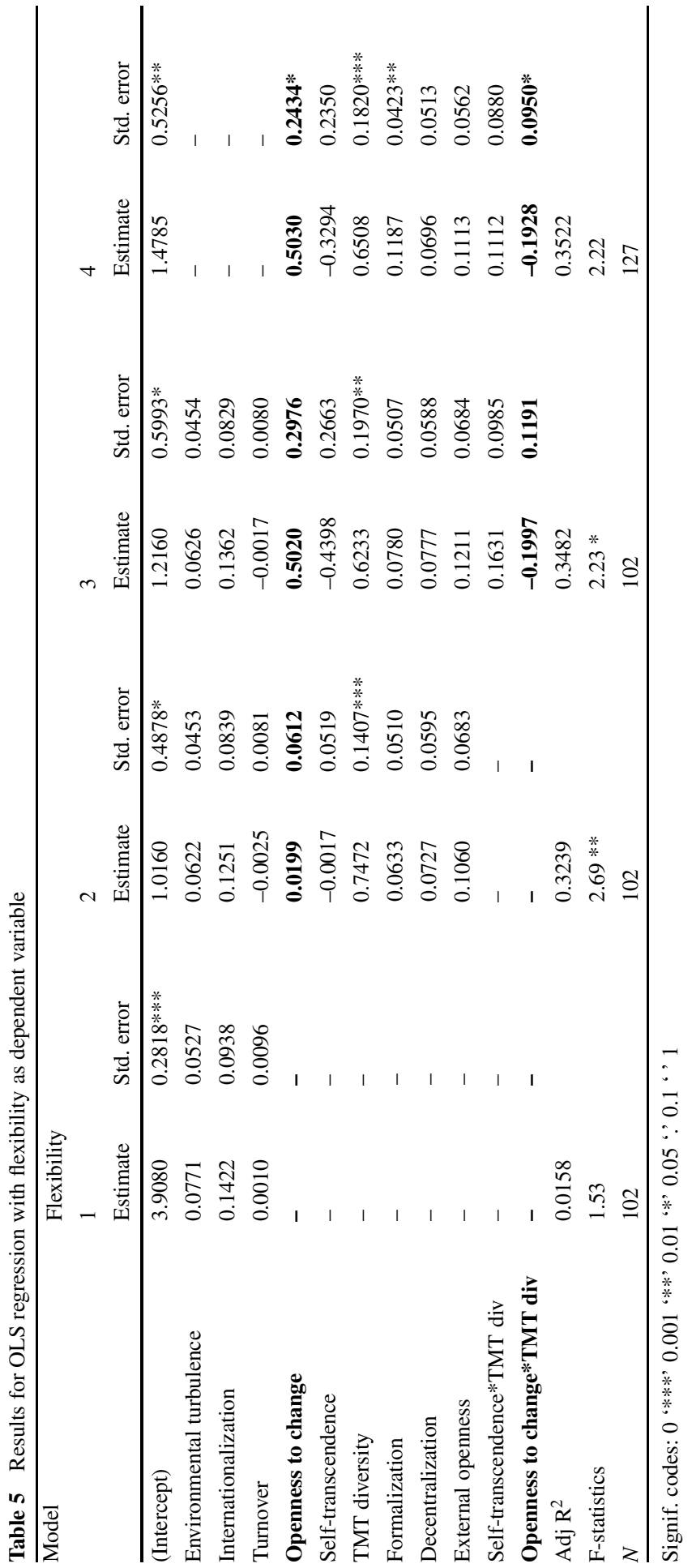




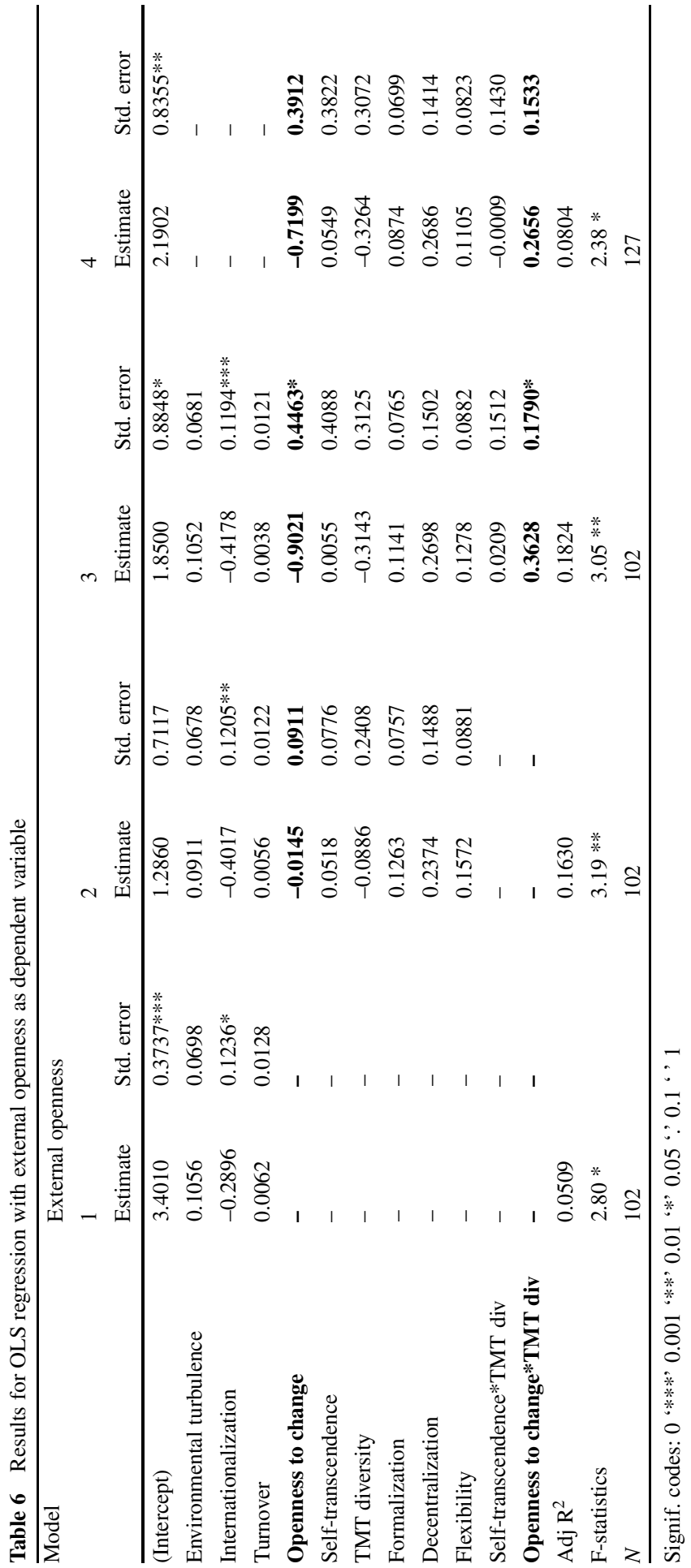


conservationist mindset. There is, however, an alternative explanation for this result, which we will look at in the discussion section below. Depending on the model, we also see positive and statistically significant associations between formalization, decentralization or flexibility and external openness. We also see a negative and significant association between internationalization and external openness, suggesting that the more internationally a corporation operates, the less likely it is to include many external stakeholders. One reason for this might be that such firms need to pay attention to the different stakeholders in each country in which they operate, who might not always share the same interests (Agle et al. 1999). These stakeholders cannot then assume a prominent role in the development of the central corporate strategy, which might well lead to relatively few of them being considered or actively involved on this aggregate level.

In short, the data provides support for our main hypotheses $\mathrm{H} 2$ and $\mathrm{H} 3$ as well as general support for our moderation hypothesis H5. We do not find support for hypotheses $\mathrm{H} 1$ and $\mathrm{H} 4$. We do, however, see support for an alternative (opposite) formulation of hypothesis H4. As outlined above, we tested extensively for common method bias and reverse causality and could not find significant differences in the overall results between our original specifications and the various tests conducted. This suggests that our results are neither driven by common method bias nor by reverse causality. Details of the full validation analysis can be found in the Appendix.

\section{Discussion and Implication of Findings}

This paper studies the effects of CEO personal values on the characteristics of corporate strategy making processes and suggests a model by which this association is moderated by TMT diversity. The model was developed on the basis of existing strategy making process models, which we enhanced with selected additions. We then tested the model using a large-scale survey. We analyzed the data using moderated OLS regressions and found some support for our model, despite a few surprising results (which we will expand upon later in this section). By integrating perspectives from upper echelon theory, values literature and strategy process research, we provide the following contributions to the literature.

First, our model does not use performance as an outcome variable, but instead uses a more proximal variable, namely the strategy making process. Many authors have argued that the inconclusive results of past upper echelon research are due in part to a focus on outcomes that are both too distal from personality factors (Wowak et al. 2016) and lack the mediating effects of process variables (Miller et al. 1998). We respond to this criticism and relate leadership characteristics to the strategy making process. In our model, we do see an association between these leadership characteristics and the proximal outcome variable. While this association is not overly strong (see limitations section), our findings still support the notion mentioned above and highlight the importance of CEOs for their corporations-an aspect which might be masked by studying too distal an outcome variable. Indeed, recent research by Quigley and Hambrick (2015) even suggests that the CEO effect on corporations has increased over the years. 
Second, we propose a model for characterizing strategy making processes that takes account of recent developments like open strategy (Whittington et al. 2011), which had not yet been around when some of the more popular strategy making frameworks (e.g. Hart 1992) were developed. So, while we do not develop an entirely new classification, we still enrich existing frameworks by including open strategy aspects in our assessment. Given the recent growing engagement of many firms with openness initiatives and the increasing attention that open strategy has been receiving from academia, we believe that the inclusion of this dimension is crucial in grasping the fullness of corporate strategy making processes (Tavakoli et al. 2015). While our research only touches the surface of the topic of open strategy, we expect to see a lot more studies in this field in the near future. We also hope that our integrative framework might be of help to researchers looking to study open strategy in detail alongside other strategy making process characteristics.

Third, our research treats CEO values explicitly instead of inferring them from demographic characteristics. It thus follows Boal and Hooijberg (2001), who call for a stop in the use of demographic variables for deducing psychosocial constructs. We believe that treating values explicitly not only provides more accurate explanations of CEO effects, but is of even greater importance now, given the multiple demands placed upon corporate leaders in times when profit maximization is decreasingly seen as the sole purpose of a firm (Carter and Greer 2013).

Fourth, we provide a fuller model for understanding the link between corporate leadership and firm outcomes. The hypothesized moderation effect of TMT diversity, which our data generally supports, is of particular importance because it explicitly addresses the interaction between the CEO and the TMT, thereby allowing a better understanding of the link between corporate leadership and strategy making. Upper echelon theory has a long history of debating the pros and cons of heterogeneity and diversity within leadership teams. It has for example been argued that greater diversity enhances a team's ability to deal with complexity, but also limits its effectiveness in execution (Carpenter et al. 2004). Our results do not easily lend themselves to interpretations of whether TMT diversity is "good" or "bad", as such an assessment would, in our case, first require an assessment of whether CEO values should be reflected in corporate strategy making processes. Arguably, this again depends on the competitive situation of the corporation. Our findings do, however, add to a nuanced treatment of TMT diversity. They are also in line with authors who suggest that, despite its advantages, TMT diversity is not universally beneficial (Ling and Kellermanns 2010), or that, at least, high levels of TMT diversity in an organization need to be dealt with efficiently (Miller et al. 1998). Future studies could focus on these aspects, thereby leveraging our tentative results and further boosting their relevance, particularly for practitioners.

Returning to the detailed results of our study, the first striking insight is that the data supports the suggested model for lower-level characteristics of corporate strategy making processes (e. g. formalization and flexibility), yet not for the highestlevel-characteristic (i.e. (de-)centralization). While this might at first glance seem to call the entire model into question, there are in fact several possible explanations for this. 
First, (de-)centralization is a key feature of organizational architecture (Lewin and Stephens 1994), and this particular aspect of strategy making is often largely a result of this overall architecture, which is sticky and very hard to change. Hence, CEOs might not even be in a position to alter it in line with their personal preferences and values, particularly in large corporations like those we studied (Vickery et al. 1999; Miller and Droege 1986). If our study had focused on start-ups or very young firms, the result might have been a different one.

Second, it can be argued that even if CEOs have the discretion to alter the level of (de-)centralization in strategy making, their own values are less likely to play a role, as practical aspects will tend to dominate. Indeed, for achievement oriented executives, Lewin and Stephens (1994, p. 191) note that they would expect the organizational design to "[...] be chosen on the basis of pragmatism, especially the CEO's perception of effectiveness." We would, for example, expect target customer groups (B2B vs. B2C), the type of products offered (standardized products vs. customized services) or the level of competition in an industry to play a much more profound role in the choice of the level of (de-)centralization (Vickery et al. 1999; Bloom et al. 2010). Following this line of thought, we should find that values only play a role for decentralization within samples of very similar firms in the same industries, size cluster, etc. While our dataset unfortunately does not permit such an investigation, future research could take this as a starting point and investigate the effect of personal values on decentralization of strategy making within certain groups of corporations.

Another possible explanation for the null result with regard to decentralization could be our decentralization construct. The reported alpha of 0.47 implies rather low reliability. In fact, it could be that decentralization with regard to strategy making cannot easily be subsumed under one simple construct, since it is a multifaceted concept that can manifest itself in various, not necessarily uniform, ways. Conducting the analysis with specific aspects of decentralization, e.g. geographic or hierarchical decentralization or decentralized decision authority vs. participation in decisions (Andersen 2004), might thus produce results that are more in line with our hypotheses. We hope to be able to explore this thought in future studies.

There are a few other findings in this paper that require further discussion. First, we observed an unexpected result for external openness (i. e. a negative association between openness to change values and external openness), which appears at first glance to be counterintuitive and contradicts our hypothesis. Indeed, one would expect a CEO with a stronger respect for openness to change to also promote a strategy making process that is externally open, as this would imply that more alternative options are being voiced and discussed. However, CEOs with a clearly defined change agenda could also be afraid that too much external openness might act as a slow-down mechanism and decelerate the pace of change (since many different ideas and views have to be considered). Similar thoughts and ideas have been voiced in relation to "optimal levels of stakeholder engagement", where coordination and dialog become increasingly costly after a certain point (Greenwood 2007).

An alternative explanation could be that, when it comes to strategy, external stakeholders are not expected to provide a great deal of positive input to change. In a forthcoming paper, Dobusch et al. (2015) compare open strategy to open inno- 
vation. They argue that while open innovation is very much about idea generation and evaluation (for which modern tools such as online platforms are often used), the purpose of open strategy is heavily focused on sensemaking. Sensemaking, however, is far less technology driven than idea generation and very often takes place in a face-to-face setting. By necessity, doing this more complex inclusion process "right" means spending more effort on each stakeholder and almost certainly working with a smaller number of stakeholders. Following this argument, the inclusion of a higher number of external stakeholders does not necessarily accelerate or propel change, and a non-conservationist CEO would not necessarily include more stakeholders. We do, however, see these possible explanations as not entirely satisfactory and thus feel that future research needs to investigate the link between CEO values and external openness in greater depth.

Second, we would like to draw particular attention to the fact that our empirical data does not show a (negative) association between openness to change values and formalization, a result that supports the notion that formalization does not imply corporate ossification. Quite the contrary, the fact that we do see a positive association between formalization and flexibility in our models even supports the notion that the two aspects of corporate strategy making are not rival, but mutually beneficial, and that flexible strategy making processes actually need formal structures to function well. Other authors have already shown such beneficial interaction (Baum and Wally 2003), and some research has even suggested that these two aspects of strategy making might well drive innovativeness together (Dibrell et al. 2014). While our empirical results with regard to this particular aspect have to be interpreted with caution, they nonetheless add to the aforementioned calls for a non-rival treatment of flexibility and formalization. These calls, in turn, cannot be stressed enough, given that the two are still popularly seen as conflicting attributes.

Overall, our results once again hint at the importance of the link between personality and strategy making. When it comes to practical relevance, they add to previous findings that different leadership teams are better suited to delivering good corporate performance depending on the circumstances (Haleblian and Finkelstein 1993), especially since it is to be expected that different strategy making styles will function better or worse in different environments. Alternatively, CEOs looking to alter their corporate strategy making process could take our results as a word of caution and use them to prepare for opposing forces, e. g. when trying to include a potentially diverse TMT in complex decisions and in the strategy making process as a whole.

\section{Limitations}

As is the case for all research, there are limitations to our study. First, and despite all our efforts to obtain a reasonable sample size, it proved very difficult to obtain responses from CEOs. While our model, despite the small sample size, shows statistically significant results, these have to be interpreted with caution, particularly with regard to their generalizability. Second, we rely on self-reported personal values and strategy making process characteristics. While we do address potential pitfalls 
with a follow-up survey, studies with longitudinal or more observational research designs (e.g. case studies) could add to and reinforce our results. That said, our results are only built on data from the German-speaking world, since a multilingual research design would have been far more complex and have brought with it potential interpretation problems (Behling and Law 2000). Nonetheless, we would like to underline that this focus on a specific European setting is also a response to the calls for more upper echelon research in non-US-settings, where studies have so far been sparse. The links between leadership characteristics and various outcome variables do have the potential to differ depending on the country, particularly as a result of the different legal and governance systems. Our results show that a strong leadership effect is also present in the German-speaking world. Nevertheless, it would be interesting to replicate our findings in other cultures and geographic areas and to check whether the identified moderation holds there as well. Future studies could go as far as to use the approach taken by Crossland and Hambrick (2011) and compare the robustness of the model across legal regimes and nations to determine the conditions under which the CEO effect and/or moderation are stronger.

Whilst we believe that our focus on the strategy making process as an outcome variable is beneficial, future work could still expand the model towards the performance side and explore possible links between CEO values (and TMT diversity) and corporate performance. Such an approach would, however, have to take care not to put too much focus on too distal outcome variables.

Finally, more needs to be known about the actual micro-level processes that link values to strategy making. While our research provides a generalized explanation of how values manifest themselves in strategy making, we do not open the black box of how the analyzed personality aspects actually influence strategy making in real-life situations (Kisfalvi and Pitcher 2003). Future research could build on our findings and take a deeper look at the mechanisms and actions of individuals by which the outlined model functions in practice. A strategy-as-practice approach which made use of case studies, observation and in-depth interviews with executives could, in particular, shed light on the inner workings of the model and provide practice-ready insights for corporate leaders.

\section{Conclusion}

Much work has been done on corporate strategy making processes, top management teams and CEO values, but none of it has so far explicitly related the three. We propose a model where CEO values have a direct influence on strategy making processes, yet where this association is moderated by TMT diversity. Data collected through a large-scale survey supports some of our hypotheses. We find effects of CEO personal values on formalization, flexibility and external openness of strategy making, but not on decentralization. Greater diversity in the TMT seems to lower the effect of the CEO's values on strategy making. Our findings add to upper echelon theory and strategy process research and allow for a better understanding of the link between corporate leadership and strategy making. 
Funding Open access funding provided by Vienna University of Economics and Business (WU).

Open Access This article is distributed under the terms of the Creative Commons Attribution 4.0 International License (http://creativecommons.org/licenses/by/4.0/), which permits unrestricted use, distribution, and reproduction in any medium, provided you give appropriate credit to the original author(s) and the source, provide a link to the Creative Commons license, and indicate if changes were made.

\section{Appendix}

\section{Validation-Sub-Sample Analysis}

A potential drawback of any single survey study relates to potential endogeneity. It could, for example, be the case that a third, unobserved factor drives the results, thus leading to omitted variable bias. In the case of our study, total reverse causality seems unlikely, as the characteristics of the strategy making process are unobservable to outsiders. Yet it could be that CEOs self-select themselves into firms that they believe to fit their own value systems (Berson et al. 2008). Alternatively, a corporation's owners or supervisory board could systematically seek out CEOs with value systems that are an apparent fit with the characteristics of the corporation. Likewise, it could indeed also be that CEO values are shaped in the long run by firm processes and culture. Despite the fact that values are something enduring, they are also not fixed and are thus subject to change and minor adaptations (Rokeach 1973).

In an ideal scenario, researchers would collect longitudinal data on strategy making process characteristics and CEO values alike to explicitly isolate causality. Unfortunately, budgetary constraints prevented such a complex approach in our research project. We did, however, apply an alternative approach to ensure that the results were indeed driven by the hypothesized relationships. Many firms in Austria and Germany are privately owned, with the owner(s) also running the corporation. In such a setting, the causality is much more straightforward. First, selection bias is not an issue as owner-managers do not choose the firm they work for and thus cannot self-select. Also, it seems rather unlikely that the values of the owner of a firm will be influenced by it. Hence, we ran the same analysis again with only family firms whose owner(s) held executive positions in the firm. This approach heavily reduced our sample size to 34 observations, leaving us with large standard errors. The results obtained (see Table 7; tests for hypotheses shown in bold) do, however, show the same signs on the relevant coefficients as in the original models, although some of them do also lose their significance. While caution in the interpretation of these results is certainly warranted, we nonetheless conclude it to be rather unlikely that we are only observing a reversely causal relationship.

\section{Validation-Follow-up Survey}

As already outlined in the paper, common method bias (or common method variance/CMV) is a problem faced by all single-survey research designs. Accordingly, we used multiple tactics to avoid this issue. The most sophisticated of these was the use of data generated in our follow-up-survey, which was conducted with a second 


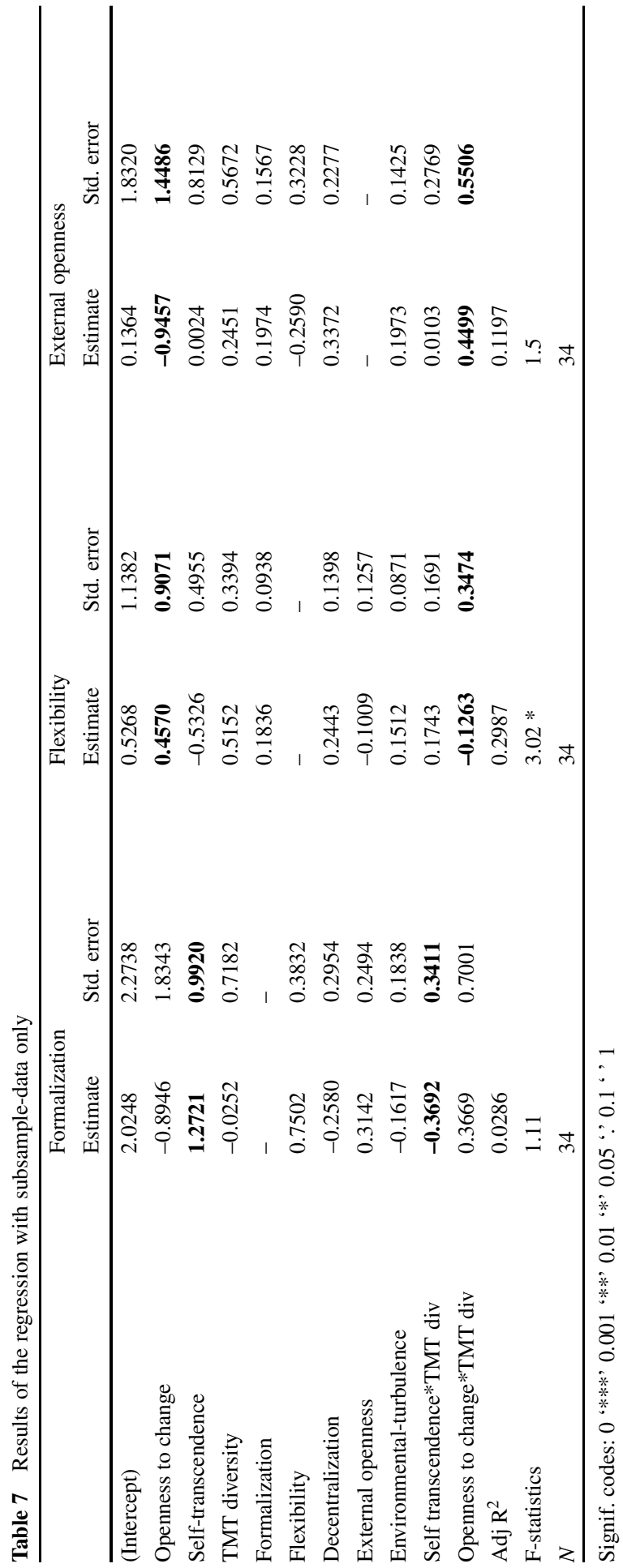




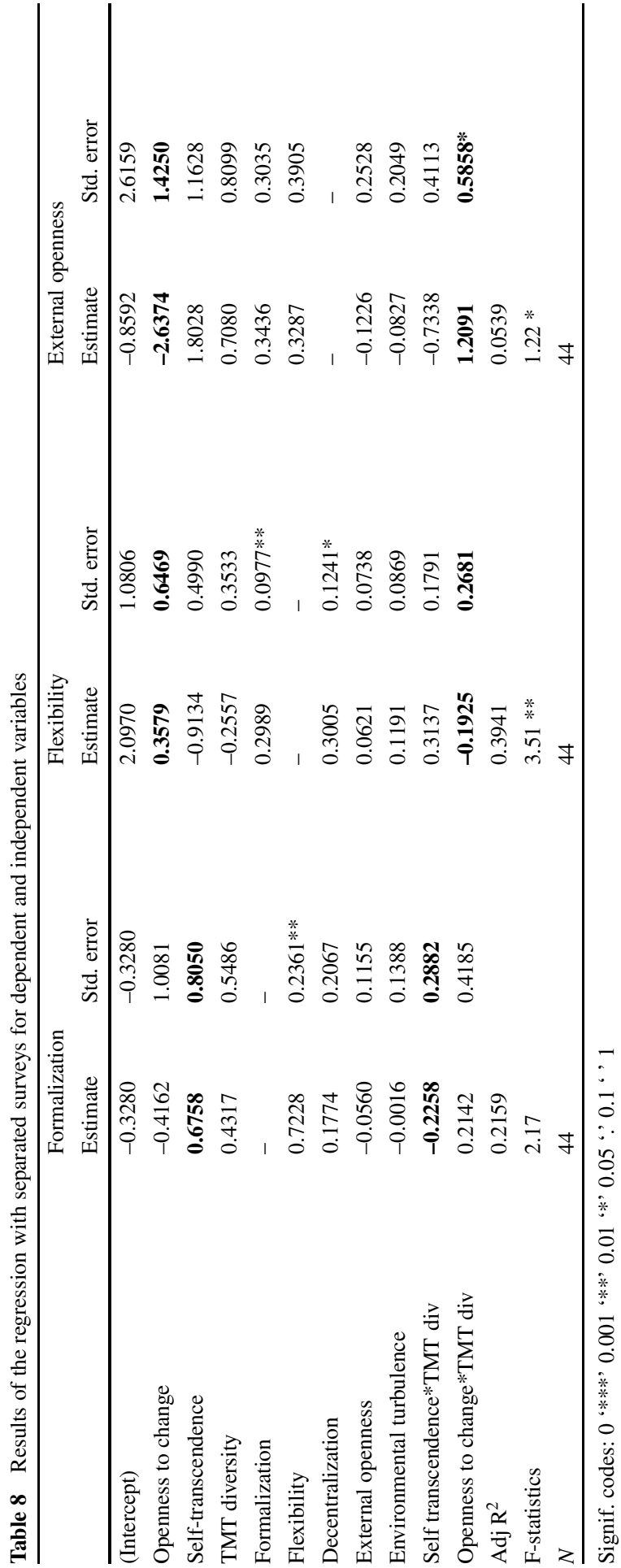


respondent in each firm five months after the original survey. The only reasons for this time lag were the need to analyze the data from the prime respondent prior to contacting the second informant and the time it took to get the replies. We do not expect the time lag to have affected the data obtained, as it seems unlikely that the characteristics of a corporation's strategy making process would change within this rather short time window.

The data obtained through this follow-up survey enabled us to fully separate the observations for dependent and independent variables. Hence, we re-ran our models with the dependent variables (characteristics of the strategy process) from the follow-up survey and the independent variables (values, TMT diversity, etc.) from the primary survey. We used the other characteristics of the strategy process as control variables in this case as well, but stuck here of course to the data generated in the follow-up survey for purposes of consistency. The results are presented in Table 8 (tests for hypotheses in bold) and do not show any statistically significant differences to the main analysis. In the formalization and flexibility models, while we see correct signs on the relevant coefficients, the effects are non-significant, which is arguably due to the much smaller sample size. For external openness, we observe the correct sign on the coefficient, and the result is even significant at the $10 \%$ level (despite the low sample size). In all of the above models, the moderation variable coefficient, with higher levels of TMT diversity lowering the association between CEO values and the strategy making process, has the correct sign. For external openness, the moderation of openness to change is also statistically significant despite the lower sample size. In short, the results from our validation analysis using the data from the follow-up survey do not contradict our original analysis, and we therefore conclude it to be rather unlikely that a systematic common method bias is driving our results.

\section{Schwartz Value Definitions and Items (Schwartz 1994)}

Achievement: personal success through demonstrating competence according to social standards.

Benevolence: preservation and enhancement of the welfare of people with whom one is in frequent personal contact.

Conformity: restraint of actions, inclinations, and impulses likely to upset or harm others and violate social expectations or norms.

Hedonism: $\quad$ pleasure and sensuous gratification for oneself.

Power:

Security:

Self-direction: independent thought and action-choosing, creating, exploring.

Stimulation: excitement, novelty, and challenge in life.

Tradition:

Universalism: understanding, appreciation, tolerance, and protection of the welfare of all people and for nature. 


\section{References}

Agle, Bradley R., Ronald K. Mitchell, and Jeffrey A. Sonnenfeld. 1999. Who Matters to CEOs? An Investigation of Stakeholder Attributes and Salience, Corporate Performance, and CEO Values. Academy of Management Journal 42(5):507-525.

Agrawal, Anup, and Chadha Sahiba. 2005. Corporate Governance and Accounting Scandals. The Journal of Law \& Economics 48(2):371-406.

Ahn, Joon Mo, Letizia Mortara, and Tim Minshall. 2013. Linkages between CEO characteristics and open innovation adoption in innovative manufacturing SMEs. Available at SSRN 2328644.

Andersen, Torben J. 2004. Integrating decentralized strategy making and strategic planning processes in dynamic environments. Journal of Management Studies 41(8):1271-1299.

Andersen, Torben J., and Bo B. Nielsen. 2009. Adaptive strategy making: The effects of emergent and intended strategy modes. European Management Review 6(2):94-106.

Ansoff, H. Igor. 1965. Corporate Strategy: Business Policy for Growth and Expansion. New York: McGraw-Hill Books.

Ansoff, H. Igor. 1980. Strategic issue management. Strategic Management Journal 1(2):131-148.

Baum, J. Robert, and Stefan Wally. 2003. Strategic decision speed and firm performance. Strategic Management Journal 24(11):1107-1129.

Behling, Orlando, and Kenneth S. Law. 2000. Translating questionnaires and other research instruments: Problems and solutions. Thousand Oaks: SAGE.

Berson, Yair, Shaul Oreg, and Taly Dvir. 2008. CEO values, organizational culture and firm outcomes. Journal of Organizational Behavior 29(5):615-633.

Bloom, Nicholas, Raffaella Sadun, and John Van Reenen. 2010. Does product market competition lead firms to decentralize? Rock Center for Corporate Governance at Stanford University Working Paper (74).

Boal, Kimberly B., and Robert Hooijberg. 2001. Strategic leadership research: Moving on. The Leadership Quarterly 11(4):515-549.

Boar, Diana. 2013. Deutsche Kurzskala des Wertefragebogens von S.H. Schwartz (Short Schwartz's Value Survey). In Handbuch Kurzskalen psychologischer Merkmale, ed. C. Kemper, M. Zenger, and E. Brähler. Berlin: Medizinisch-Wissenschaftliche Verlagsgesellschaft.

Boeker, Warren. 1997. Strategic change: The influence of managerial characteristics and organizational growth. Academy of Management Journal 40(1):152-170.

Burgelman, Robert A. 1983. A process model of internal corporate venturing in the diversified major firm. Administrative Science Quarterly 28(2):223-244.

Burgelman, Robert A. 1996. A process model of strategic business exit: Implications for an evolutionary perspective on strategy. Strategic Management Journal 17(S1):193-214.

Buyl, Tine, Christophe Boone, Walter Hendriks, and Paul Matthyssens. 2011. Top Management Team Functional Diversity and Firm Performance: The Moderating Role of CEO Characteristics. Journal of Management Studies 48(1):151-177.

Carlson, Dawn S., and Pamela L. Perrewe. 1995. Institutionalization of organizational ethics through transformational leadership. Journal of Business Ethics 14(10):829-838.

Carpenter, Mason A. 2002. The implications of strategy and social context for the relationship between top management team heterogeneity and firm performance. Strategic Management Journal 23(3):275-284.

Carpenter, Mason A., Marta A. Geletkanycz, and W. M. Gerard Sanders. 2004. Upper echelons research revisited: Antecedents, elements, and consequences of top management team composition. Journal of Management 30(6):749-778.

Carter, Suzanne M., and Charles R. Greer. 2013. Strategic Leadership: Values, Styles, and Organizational Performance. Journal of Leadership \& Organizational Studies 20(4):375-393. https://doi.org/ $10.1177 / 1548051812471724$.

Chakravarthy, Balaji S., and Yves Doz. 1992. Strategy process research: Focusing on corporate self-renewal. Strategic Management Journal 13(S1):5-14.

Chan, David. 2009. So why ask me? Are self-report data really that bad. In Statistical and methodological myths and urban legends: Doctrine, verity and fable in the organizational and social sciences, ed. Charles E. Lance, Robert J. Vandenberg, 309-336. New York: Routledge.

Chatterjee, Arijit, and Donald C. Hambrick. 2007. It's All about Me: Narcissistic Chief Executive Officers and Their Effects on Company Strategy and Performance. Administrative Science Quarterly 52(3):351-386. 
Chesbrough, Henry W., and Melissa M. Appleyard. 2007. Open innovation and strategy. California Management Review 50(1):57-76.

Chin, M.K., Donald C. Hambrick, and Linda K. Treviño. 2013. Political Ideologies of CEOs The Influence of Executives' Values on Corporate Social Responsibility. Administrative Science Quarterly 58(2):197-232.

Covin, Jeffrey G., Kimberly M. Green, and Dennis P. Slevin. 2006. Strategic Process Effects on the Entrepreneurial Orientation-Sales Growth Rate Relationship. Entrepreneurship Theory and Practice 30(1):57-81.

Crossland, Craig, and Donald C. Hambrick. 2011. Differences in managerial discretion across countries: how nation-level institutions affect the degree to which ceos matter. Strategic Management Journal 32(8):797-819.

Cyert, Richard M., and James G. March. 1963. A behavioral theory of the firm, 2nd edn., Englewood Cliffs: Wiley-Blackwell.

Dawson, Jeremy F. 2014. Moderation in Management Research: What, Why, When, and How. Journal of Business and Psychology 29(1):1-19.

Dess, Gregory G., G.T. Lumpkin, and J.G. Covin. 1997. Entrepreneurial Strategy Making and Firm Performance: Tests of Contingency and Configurational Models. Strategic Management Journal 18(9):677-695.

Dibrell, Clay, Justin B. Craig, and Donald O. Neubaum. 2014. Linking the formal strategic planning process, planning flexibility, and innovativeness to firm performance. Journal of Business Research 67(9):2000-2007.

Dobusch, Leonhard, David Seidl, and Felix Werle. 2015. Opening up the strategy-making process: Comparing open strategy to open innovation. University of Zurich, Institute of Business Administration, UZH Business Working Paper (359).

Doz, Yves L., and Kosonen Mikko. 2008. Fast strategy: How strategic agility will help you stay ahead of the game. London: Pearson Education.

Falshaw, J. Richard, Keith W. Glaister, and Tatoglu Ekrem. 2006. Evidence on formal strategic planning and company performance. Management Decision 44(1):9-30.

Farber, David B. 2005. Restoring Trust after Fraud: Does Corporate Governance Matter? The Accounting Review 80(2):539-561.

Field, Andy. 2013. Discovering statistics using IBM SPSS statistics. Thousand Oaks: SAGE.

Finkelstein, Sydney, and Donald C. Hambrick. 1990. Top-management-team tenure and organizational outcomes: The moderating role of managerial discretion. Administrative Science Quarterly 35(3):484-503. https://doi.org/10.2307/2393314.

Finkelstein, Sydney, and Donald C. Hambrick. 1996. Strategic Leadership: Top Executives and Their Effects on Organizations. Eagan: West Publishing Company.

Floyd, Steven W., and Peter J. Lane. 2000. Strategizing throughout the organization: Managing role conflict in strategic renewal. Academy of Management Review 25(1):154-177.

Freeman, R. Edward, Jeffrey S. Harrison, Andrew C. Wicks, Bidhan L. Parmar, and Simone De Colle. 2010. Stakeholder Theory: the state of the art. Cambridge: Cambridge University Press.

Friedman, Stewart D., and Singh Harbir. 1989. CEO Succession and Stockholder Reaction: The Influence of Organizational Context and Event Content. The Academy of Management Journal 32(4):718-744.

Greenwood, Michelle. 2007. Stakeholder engagement: Beyond the myth of corporate responsibility. Journal of Business Ethics 74(4):315-327.

Gupta, Anil K. 1984. Contingency linkages between strategy and general manager characteristics: A conceptual examination. Academy of Management Review 9(3):399-412.

Guth, William D., and Ian C. MacMillan. 1986. Strategy Implementation Versus Middle Management SelfInterest. Strategic Management Journal 7(4):313-327.

Haleblian, Jerayr, and Sydney Finkelstein. 1993. Top management team size, CEO dominance, and firm performance: The moderating roles of environmental turbulence and discretion. Academy of Management Journal 36(4):844-863.

Hambrick, Donald C., and Gerard L. Brandon. 1988. Executive values. In D. C. Hambrick (Ed.), Strategic management policy and planning, Vol. 2. The executive effect: Concepts and methods for studying top managers (pp. 3-34). Greenwich, CT: Elsevier Science/JAI Press.

Hambrick, Donald C., and Sydney Finkelstein. 1987. Managerial discretion: A bridge between polar views of organizational outcomes. Research in organizational behavior 9:369-406.

Hambrick, Donald C., and Phyllis A. Mason. 1984. Upper Echelons: The Organization as a Reflection of Its Top Managers. Academy of Management Review 9(2):193-206. 
Hambrick, Donald C., and Timothy J. Quigley. 2014. Toward more accurate contextualization of the CEO effect on firm performance. Strategic Management Journal 35(4):473-491.

Hambrick, Donald C., Theresa S. Cho, and Chen Ming-Jer. 1996. The influence of top management team heterogeneity on firms' competitive moves. Administrative Science Quarterly 41(4):659-684.

Hannan, Michael T., and John Freeman. 1984. Structural inertia and organizational change. American sociological review 49(2):149-164.

Hart, Stuart L. 1992. An Integrative Framework for Strategy-Making Processes. Academy of Management Review 17(2):327-351.

Hart, Stuart L., and Catherine Banbury. 1994. How Strategy-Making Processes Can Make a Difference. Strategic Management Journal 15(4):251-269.

Hemingway, Christine A., and Patrick W. Maclagan. 2004. Managers' Personal Values as Drivers of Corporate Social Responsibility. Journal of Business Ethics 50(1):33-44.

Hofstede, Geert. 1984. Culture's consequences: International differences in work-related values. Thousand Oaks: SAGE.

Hood, Jacqueline N. 2003. The Relationship of Leadership Style and CEO Values to Ethical Practices in Organizations. Journal of Business Ethics 43(4):263-273.

Hutzschenreuter, Thomas, and Ingo Kleindienst. 2006. Strategy-Process Research: What Have We Learned and What Is Still to Be Explored. Journal of Management 32(5):673-720.

Inglehart, Ronald. 2004. Human beliefs and values: A cross-cultural sourcebook based on the 1999-2002 values surveys. Mexico City: Siglo XXI.

Jackson, Susan E., Joshi, Aparna, and L. Erhardt Niclas. 2003. Recent research on team and organizational diversity: SWOT analysis and implications. Journal of Management 29(6):801-830.

Kaldschmidt, Susanne. 2011. The values of sustainability - The influence of leaders' personal values on sustainability strategies. PhD Dissertation, University of St. Gallen.

Kisfalvi, Veronika, and Patricia Pitcher. 2003. Doing What Feels Right The Influence of CEO Character and Emotions on Top Management Team Dynamics. Journal of Management Inquiry 12(1):42-66.

Knight, Don, Craig L. Pearce, Ken G. Smith, Judy D. Olian, Henry P. Sims, Ken A. Smith, and Patrick Flood. 1999. Top management team diversity, group process, and strategic consensus. Strategic Management Journal 20(5):445-465.

Kraus, Sascha, Rainer Harms, and Erich Schwarz. 2006. Strategic planning in smaller enterprises - new empirical findings. Management Research News 29(6):334-344.

Laursen, Keld, and Ammon Salter. 2006. Open for innovation: the role of openness in explaining innovation performance among U.K. manufacturing firms. Strategic Management Journal 27(2):131-150.

Layard, Peter R.G., and Richard Layard. 2011. Happiness: Lessons from a new science. London: Penguin.

Lefebvre, Elisabeth, and Louis A. Lefebvre. 1992. Firm innovativeness and CEO characteristics in small manufacturing firms. Journal of Engineering and Technology Management 9(3):243-277.

Lewin, Arie Y., and Carroll U. Stephens. 1994. CEO attitudes as determinants of organization design: An integrated model. Organization Studies 15(2):183-212.

Lindeman, Marjaana, and Markku Verkasalo. 2005. Measuring Values With the Short Schwartz's Value Survey. Journal of Personality Assessment 85(2):170-178.

Ling, Yan, and Franz W. Kellermanns. 2010. The effects of family firm specific sources of TMT diversity: The moderating role of information exchange frequency. Journal of Management Studies 47(2):322-344.

Ling, Yan, Hao Zhao, and Robert A. Baron. 2007. Influence of Founder-CEOs' Personal Values on Firm Performance: Moderating Effects of Firm Age and Size. Journal of Management 33(5):673-696.

Maak, Thomas. 2007. Responsible Leadership, Stakeholder Engagement, and the Emergence of Social Capital. Journal of Business Ethics 74(4):329-343.

March, James G., and Herbert A. Simon. 1958. Organizations. Hoboken: Wiley-Blackwell.

Matzler, Kurt, Johann Füller, Britta Koch, Julia Hautz, and Katja Hutter. 2014. Open Strategy - A New Strategy Paradigm? In Strategie und Leadership, ed. Kurt Matzler, Harald Pechlaner, and Birgit Renzl, 37-55. Wiesbaden: Springer.

McCrae, Robert R., and Paul T. Costa. 1996. Toward a New Generation of Personality Theories: Theoretical Contexts for the Five-Factor Model. In The Five-Factor Model of Personality: Theoretical Perspectives, ed. J.S. Wiggins. New York: Guilford.

Miller, Danny. 1991. Stale in the saddle: CEO tenure and the match between organization and environment. Management science 37(1):34-52.

Miller, Danny, and Cornelia Droege. 1986. Psychological and Traditional Determinants of Structure. Administrative Science Quarterly 31(4):539-560. 
Miller, Danny, and Peter H. Friesen. 1983. Strategy-Making and Environment: The Third Link. Strategic Management Journal 4(3):221-235.

Miller, Danny, and Jean-Marie Toulouse. 1986. Chief executive personality and corporate strategy and structure in small firms. Management science 32(11):1389-1409.

Miller, C. Chet, Linda M. Burke, and William H. Glick. 1998. Cognitive diversity among upper-echelon executives: Implications for strategic decision processes. Strategic Management Journal:39-58. https://doi.org/10.1002/(SICI)1097-0266(199801)19:1<39::AID-SMJ932>3.0.CO;2-A

Mintzberg, Henry. 1973. Strategy-making in three modes. California Management Review 16(2):44-53.

Mintzberg, Henry. 1978. Patterns in strategy formation. Management science 24(9):934-948.

Mintzberg, Henry. 1983. Power in and around organizations. Englewood Cliffs: Prentice-Hall.

Mintzberg, Henry. 1994. Rise and fall of strategic planning. New York: Simon and Schuster.

Nielsen, Sabina. 2010. Top management team diversity: A review of theories and methodologies. International Journal of Management Reviews 12(3):301-316.

Olver, James M., and Todd A. Mooradian. 2003. Personality traits and personal values: a conceptual and empirical integration. Personality and individual differences 35(1):109-125.

Papadakis, Vassilis M. 2006. Do CEOs shape the process of making strategic decisions? Evidence from Greece. Management Decision 44(3):367-394.

Papadakis, Vasilis M., and Patrick Barwise. 2002. How much do CEOs and top managers matter in strategic decision-making? British Journal of Management 13(1):83-95.

Papadakis, Vassilis M., Spyros Lioukas, and David Chambers. 1998. Strategic decision-making processes: the role of management and context. Strategic Management Journal 19(2):115-147.

Peterson, Randall S., D. Brent Smith, Paul V. Martorana, and Pamela D. Owens. 2003. The impact of chief executive officer personality on top management team dynamics: one mechanism by which leadership affects organizational performance. Journal of Applied Psychology 88(5):795.

Pettigrew, Andrew M. 1997. What is a processual analysis? Scandinavian Journal of Management 13(4):337-348.

Podsakoff, Philip M., Scott B. MacKenzie, Jeong-Yeon Lee, and Nathan P. Podsakoff. 2003. Common method biases in behavioral research: a critical review of the literature and recommended remedies. Journal of Applied Psychology 88(5):879.

Quigley, Timothy J., and Donald C. Hambrick. 2015. Has the "CEO effect" increased in recent decades? A new explanation for the great rise in America's attention to corporate leaders. Strategic Management Journal 36(6):821-830.

Roccas, Sonia. 2003. Identification and status revisited: The moderating role of self-enhancement and selftranscendence values. Personality and Social Psychology Bulletin 29(6):726-736.

Roccas, Sonia, Lilach Sagiv, Shalom H. Schwartz, and Knafo Ariel. 2002. The big five personality factors and personal values. Personality and Social Psychology Bulletin 28(6):789-801.

Rohan, Meg J. 2000. A rose by any name? The values construct. Personality and social psychology review 4(3):255-277.

Rokeach, Milton. 1973. The nature of human values. New York: Free Press.

Sanders, W. M. Gerard, and Mason A. Carpenter. 1998. Internationalization and Firm Governance: The Roles of CEO Compensation, Top Team Composition, and Board Structure. The Academy of Management Journal 41(2):158-178.

Sashkin, M. 1988. The visionary leader. In The Jossey-Bass management series. Charismatic leadership: The elusive factor in organizational effectiveness, eds. J. A. Conger \& R. N. Kanungo, 122-160. San Francisco: Jossey-Bass.

Schein, Edgar H. 2009. The corporate culture survival guide. Hoboken: John Wiley \& Sons.

Schein, Edgar H. 2010. Organizational culture and leadership. Hoboken: John Wiley \& Sons.

Schwartz, Shalom H. 1992. Universals in the content and structure of values: Theoretical advances and empirical tests in 20 countries. Advances in experimental social psychology 25(1):1-65.

Schwartz, Shalom H. 1994. Are there universal aspects in the structure and contents of human values? Journal of social issues 50(4):19-45.

Schwartz, Shalom H. 2013. Human Values. http://essedunet.nsd.uib.no/cms/topics/1/1/all.html. Accessed 11.10.2016.

Schwartz, Shalom H., and Wolfgang Bilsky. 1990. Toward a theory of the universal content and structure of values: Extensions and cross-cultural replications. Journal of personality and social psychology 58(5):878.

Schwartz, Shalom H., and Sagiv Lilach. 1995. Identifying culture-specifics in the content and structure of values. Journal of cross-cultural psychology 26(1):92-116. 
Sharfman, Mark P., and James W. Dean Jr.. 1997. Flexibility in Strategic Decision Making: Informational and Ideological Perspectives. Journal of Management Studies 34(2):191-217.

Six, Bjoern, Marcel Normann, Ruth M. Stock, and Dirk Schiereck. 2013. Strategic Leaders' Impact on Corporate Policies and Firm Performance: Insights from CEOs and CFOs of Large Listed Firms in Germany. Schmalenbach Business Review 65:82-111.

Tacheva, Sabina. 2007. Top management team diversity: A multilevel exploration of antecedents and consequences. University of St. Gallen.

Tavakoli, Asin, Schlagwein, Daniel, and Schoder, Detlef. 2015. Open Strategy: Consolidated Definition and Processual Conceptualization: University of Cologne.

Van de Ven, Andrew H. 1992. Suggestions for studying strategy process: a research note. Strategic Management Journal 13(5):169-188.

Vickery, Shawnee, Cornelia Dröge, and Richard Germain. 1999. The relationship between product customization and organizational structure. Journal of Operations Management 17(4):377-391.

Wagner, Stephan M., and René Kemmerling. 2010. Handling nonresponse in logistics research. Journal of Business Logistics 31(2):357-381.

Wally, Stefan, and J. Robert Baum. 1994. Personal and Structural Determinants of the Pace of Strategic Decision Making. The Academy of Management Journal 37(4):932-956.

Watson, George W., Robyn A. Berkley, and Steven D. Papamarcos. 2009. Ambiguous allure: The value-pragmatics model of ethical decision making. Business and Society Review 114(1):1-29.

Whittington, Richard, Ludovic Cailluet, and Yakis Douglas Basak. 2011. Opening strategy: Evolution of a precarious profession. British Journal of Management 22(3):531-544.

Williams, Katherine Y., and Charles A. O'Reilly. 1998. Demography and diversity in organizations: A review of 40 years of research. Research in organizational behavior 20:77-140.

Williamson, Oliver E. 1970. Corporate control and business behavior: An inquiry into the effects of organization form on enterprise behavior. Englewood Cliffs, NJ: Prentice Hall.

Wowak, Adam J., Michael J. Mannor, Mathias Arrfelt, and Gerry McNamara. 2016. Earthquake or glacier? How CEO charisma manifests in firm strategy over time. Strategic Management Journal 37(3):586-603. 